\title{
Crecimiento en crustáceos decápodos: resultados de investigaciones realizadas en Argentina*
}

\author{
Ana M. Petriella ${ }^{1}$ E Enrique E. Boschi ${ }^{2}$ \\ ${ }^{1}$ Departamento de Ciencias Marinas, Universidad Nacional de Mar del Plata \\ Consejo Nacional de Investigaciones Científicas y Técnicas \\ Funes 3350, 7600 Mar del Plata, Argentina \\ ${ }^{2}$ Consejo Nacional de Investigaciones Científicas y Técnicas \\ Instituto Nacional de Investigación y Desarrollo Pesquero. Universidad de Buenos Aires \\ Casilla de Correo 175, 7600 Mar del Plata, Argentina
}

\begin{abstract}
RESUMEN. El trabajo se refiere a los aspectos biológicos del crecimiento y a los métodos empleados para estudiar el aumento de tamaño en los crustáceos Decápodos del mar epicontinental argentino.

Primeramente se reseñan los mecanismos endócrinos que controlan y desencadenan la muda. Luego se describen las características distintivas del crecimiento en los crustáceos, que se produce en forma discontinua y sujeto a las sucesivas mudas (cambio del exoesqueleto). Se mencionan los métodos usados por distintos autores, especialmente los referidos a especies argentinas, incluyendo algunos de los métodos cuantitativos empleados en Argentina para analizar el crecimiento.

Se presentan ejemplos sobre el dimorfismo sexual y caracteres sexuales secundarios permanentes o transitorios relacionados con el ciclo reproductivo de algunas especies.

Finalmente, se destaca la influencia de las condiciones ambientales (temperatura, salinidad, contaminación) y de otros factores tales como la nutrición, la pérdida de apéndices y el parasitismo sobre el crecimiento.
\end{abstract}

Palabras claves: crustáceos, decápodos, crecimiento, edad, métodos, Argentina.

\section{Growth of decapod crustaceans: results of research made on Argentine species*}

\begin{abstract}
The paper deals with the aspect related to the growth and methods used to estimate the size and weight increment of the Decapod crustaceans in the Argentine Sea (Southwest Atlantic Ocean).

At first are mentioned the endocrine mechanism which promote and control the molting cycle. Comments are made on the characteristcs of the discontinuous growth in crustaceans, depending on successive moults, i.e. changes of the exoskeleton. Details are given of the methods used by different authors, especially those on argentine species, including some methods quantitative of analysis of growth.

Examples are given for sexual dimorphism and secondary sexual characters, permanent or transitory, which are related to the reproductive cycle in some species.

Finally, influences of environmental conditions on growth are reviewed: temperature, ligth, salinity, pressure, pollution and other factor related to nutrition, limb loss, and parasitism.
\end{abstract}

Key words: crustacean, decapods, growth, age, methods, Argentine.

\footnotetext{
* Contribución INIDEP N¹011
} 


\section{INTRODUCCION}

Uno de los parámetros más importantes en el estudio de la dinámica de las poblaciones de animales sometidos a explotación, es el crecimiento. En el caso particular de los crustáceos el crecimiento se observa como un proceso discontinuo que ocurre por saltos, debido a que el exoesqueleto o caparazón rígido que lo recubre no permite que el aumento en largo o peso se manifieste en forma continua.

El crecimiento de los crustáceos se advierte, entonces, como un incremento de talla, peso y forma casi instantáneos y ocurre cuando se produce la muda, exuviación o ecdisis, que implica el abandono y degradación del viejo exoesqueleto y síntesis de nuevos tejidos. Todo el mecanismo de muda está regido por un complejo sistema endocrino y la ecdisis no puede considerarse como un evento aislado, sino como una etapa más de un ciclo continuo de actividad metabólica, regulado por procesos hormonales.

\section{CRECIMIENTO DE CRUSTACEOS DECAPODOS}

\section{La muda y el crecimiento}

Una de las particularidades de la presencia de un exoesqueleto rígido en los crustáceos es, entre otras, la restricción del crecimiento a períodos bien definidos. Naturalmente, esta característica implica la eliminación del antiguo exoesqueleto y la formación de un tegumento nuevo y generalmente de mayor tamaño, siendo el conjunto de estos sucesos conocido como ciclo de muda. Este fenómeno es cíclico, alternándose fases de relativo reposo externo con otras de intensa actividad. A partir de numerosos trabajos de índole morfológica y fisiológica, iniciados por Olmsted y Baumberger (1923) se han podido caracterizar los diferentes estadíos del ciclo de muda.

Drach (1939), trabajando con Cancer pagurus y Maia squinado introdujo el concepto de intermuda, como la secuencia de transformaciones comprendidas entre dos mudas, en cuyo período se cumple un ciclo completo de modificaciones morfológicas, fisiológicas y bioquímicas, responsables del crecimiento.

Usualmente, el intervalo entre dos mudas sucesivas puede ser dividido en tres etapas: postmuda, intermuda y premuda. Empleando la nomenclatura y los criterios establecidos por Drach $(1939 ; 1944)$ y Drach y Tchernigovtzeff (1967) se reconocen cinco estadíos (A, B, C, D y E).

Los estadíos A y B corresponden a la postmuda; el estadío C a la intermuda; el estadío D a la premuda y el estadío $\mathrm{E}$ al momento de la ecdisis.

La caracterización de esos estadíos puede resumirse del modo siguiente:

Estadío A: el animal acaba de abandonar la exuvia, continuando la secreción de la nueva cutícula.

Estadío B: comienzan a endurecerse las diferentes capas de la nueva cutícula.

Estadío C: todo el exoesqueleto se engrosa y endurece. Hay crecimiento de tejidos y acumulación de reservas.

Estadío D: se reabsorben los minerales y materiales orgánicos del exoesqueleto y se deposita parcialmente el nuevo exoesqueleto, debajo del viejo.

EstadíoE:el animal se desprende del viejo exoesqueleto; es el momento de la exuviación.

En la Fig. 1 se muestra una hembra de centolla Lithodes santolla en el momento de la muda.

Cada uno de estos períodos puede reconocerse, y a su vez dividirse en subestadíos, por cambios tegumentarios externos (grado de rigidez, pigmentación) o internos, como la formación de las nuevas sedas o setogénesis, que permite seguir el ciclo por observación microscópica directa de los cambios operados en los apéndices (Aiken,1973; Reaka,1975; Dexter, 1981).

Debido a los profundos cambios metabólicos asociados a cada estadío, actualmente se considera indispensable la caracterización morfológica del ciclo como paso previo al estudio del crecimiento.

Los criterios de reconocimiento de los estadíos del ciclo de muda de especies de crustáceos decápodos de la Argentina se han establecido para el camarón Artemesia longinaris en (Petriella 1984), el langostino Pleoticus muelleri por (Díaz y Petriella 1990) y el camarón de agua dulce Palaemonetes argentinus en (Díaz y Petriella, datos inéditos).

\section{Control endocrino de la muda}

La exuviación, como se ha dicho, es solamente la manifestación de un complejo proceso que se inicia varios días o semanas antes. Esencialmente todos los tejidos están involucrados en la preparación de la muda siguiente: hay movilización de reservas, aumento de la división celular y modificación del com- 


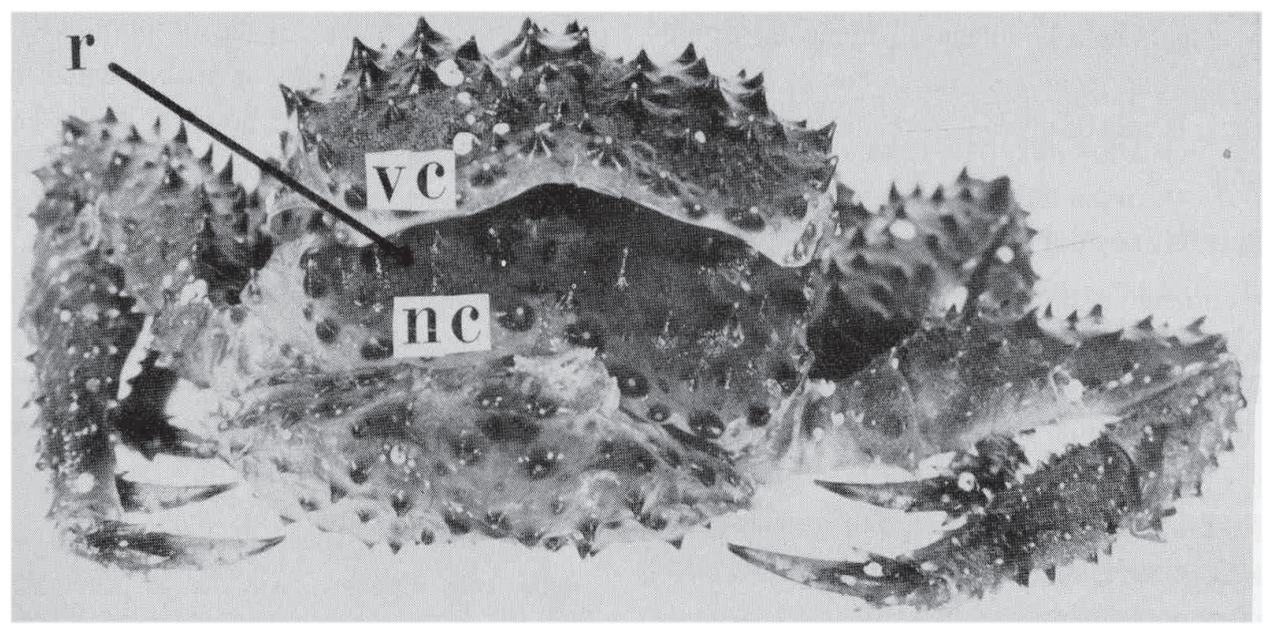

Figura 1. Hembra de centolla Lithodes santolla en el momento de la muda. La flecha (r) indica la ruptura entre el caparazón viejo (vc) y el nuevo (nc).

Figure 1. Antarctic king crab female Lithodes santolla molting. The arrow (r) indicates the rupture between the old carapace (vc) and the new carapace (nc).

portamiento. Como en el resto de los animales, la coordinación de la serie de eventos necesarios para la ecdisis a través del tiempo de la intermuda, se efectúa mediante un sistema hormonal (Chang, 1991). El modelo aceptado actualmente sobre el control de la muda de los crustáceos, postula la siguiente interacción:

La hormona de la muda (HM), cuya síntesis se inicia en el órgano $\mathrm{Y}$, es usualmente reprimida por la hormona inhibidora de la muda (HIM) que se origina en el órgano $\mathrm{X}$, localizado en los pedúnculos oculares.

- $\quad$ La actividad de la hormona inhibidora de la muda, promueve la formación de nuevos tejidos e inhibe la actividad secretora del órgano Y. Cuando el nivel de hormona inhibidora de la muda de la hemolinfa disminuye, el órgano Y libera una dosis de hormona de la muda que desencadena la preparación a una nueva ecdisis.

- El órgano Y secreta un ecdisteroide, precursor de la hormona de la muda, caracterizado como ecdisona, que es transformado en otros tejidos, a su forma activa, la 20-hidroxiecdisona, ecdisterona o crustecdisona.

- Cuando el órgano X, por cualquier motivo,reduce la síntesis y secreción de la HIM, la hormona de la muda inicia la serie de sucesos coordinados que conducen a la ecdisis.

La concentración de la hormona de la muda en la hemolinfa varía drásticamente durante el transcurso del ciclo de muda. En la postmuda, inmediatamente después de la ecdisis, su concentración es mínima; luego hay un súbito incremento, alcanzando la máxima concentración durante la premuda, para luego disminuir, en forma abrupta, poco antes de la muda. Estos cambios en la concentración de la $\mathrm{HM}$ han sido demostrados para varias especies de decápodos y se acepta que corresponden a un modelo general del grupo.

Las alteraciones de la concentración de hormona de la muda podrían ser reguladas tanto por los cambios en la tasa de síntesis y/o liberación de la hormona como por la tasa de hidroxilación de ecdisona a 20-hidroxiecdisona y su degradación en la hemolinfa. Skinner et al. (1985) y Lachaise et al. (1993) han realizado importantes revisiones sobre este tema.

Como se ha mencionado, la regulación de la síntesis de la HM se efectúa por medio de una hormona inhibidora, de naturaleza peptídica, sintetizada en un órgano neurosecretor, el órgano $\mathrm{X}$ y almacenada en un órgano neurohemal o glándula del seno, también localizada en el pedúnculo ocular. Las primeras pruebas de la naturaleza inhibitoria de sustancias formadas en el pedúnculo ocular fueron obtenidas en 1905 por Zeleny (Skinner, 1985) quien, accidentalmente, comprobó que los animales sometidos a ablación peduncular mudaban más frecuentemente que los intactos. Esta respuesta ha sido lograda posteriormente con un sinnúmero de 
especies y actualmente la ablación peduncular se emplea como una técnica de rutina con el objeto de modificar la tasa de muda y correlativamente el crecimiento.

\section{Características del crecimiento}

El crecimiento se manifiesta como el aumento en longitud, volumen o peso. En organismos sin exoesqueleto la longitud aumenta en forma continua, aunque con una tasa que disminuye con la edad, hasta que en los adultos generalmente se detiene. En los crustáceos, que poseen un tegumento inextensible, el crecimiento se transforma en un proceso aparentemente discontinuo.

El crecimiento en estos artrópodos se vincula directamente al proceso de muda, ya que durante el ciclo de vida hay una sucesión de mudas (o ecdisis) separadas por intermudas, que son más frecuentes en las primeras etapas de la vida del animal y disminuyen o están totalmente ausentes en los adultos (Fig. 2). En cada muda el viejo exoesqueleto es eliminado y tiene lugar un súbito incremento de tamaño como resultado de la absorción de agua, que ocurre antes de que el nuevo tegumento se endurezca por incorporación de sales de calcio que se concentran en la hemolinfa, y en algunas especies en los gastrolitos, glándulas digestivas u otros depósitos, durante el período de muda (Stevenson, 1985). Luego de ello, las dimensiones del animal permanecen aproximadamente constantes hasta la próxima muda.

El sistema usual para estudiar el crecimiento absoluto en crustáceos decápodos, es emplear una única dimensión del exoesqueleto, como la longitud del caparazón o longitud total, que suma la del caparazón a la del pleon, o el peso, como índice de crecimiento. Cuando se trata de determinar el crecimiento relativo se suele medir el largo y ancho de los quelípedos, largo y ancho del caparazón o cualquier otra estructura que refleje mejor los cambios morfológicos relacionados con el crecimiento y la edad.

El cambio sucesivo del caparazón que recubre todo el cuerpo tiene importantes implicancias en el estudio del crecimiento. La carencia de estructuras calcificadas permanentes imposibilita el análisis de marcas que indiquen aumento de talla, como ocurre con otros grupos de animales: conchillas o valvas de moluscos o las escamas, huesos y otolitos de peces. En crustáceos, se ha intentado, sin éxito, determinar la deposición de lamelas de la endocutícula
(Yano y Kobayashi, 1965; Farmer, 1973).

Debido a la carácterística discontinua del crecimiento de los crustáceos, se distinguen dos componentes fundamentales. Uno es el incremento que puede ocurrir en cada muda. El otro es el lapso de intermuda o intervalo de muda, que es el período comprendido entre dos mudas sucesivas. Esos dos componentes del proceso de crecimiento son básicamente contrapuestos, con respuestas muy diferentes a cambios externos, lo que requiere un análisis independiente (Hartnoll, 1982).

Es necesario destacar que existen mudas sin incremento de talla o peso, particularmente en los

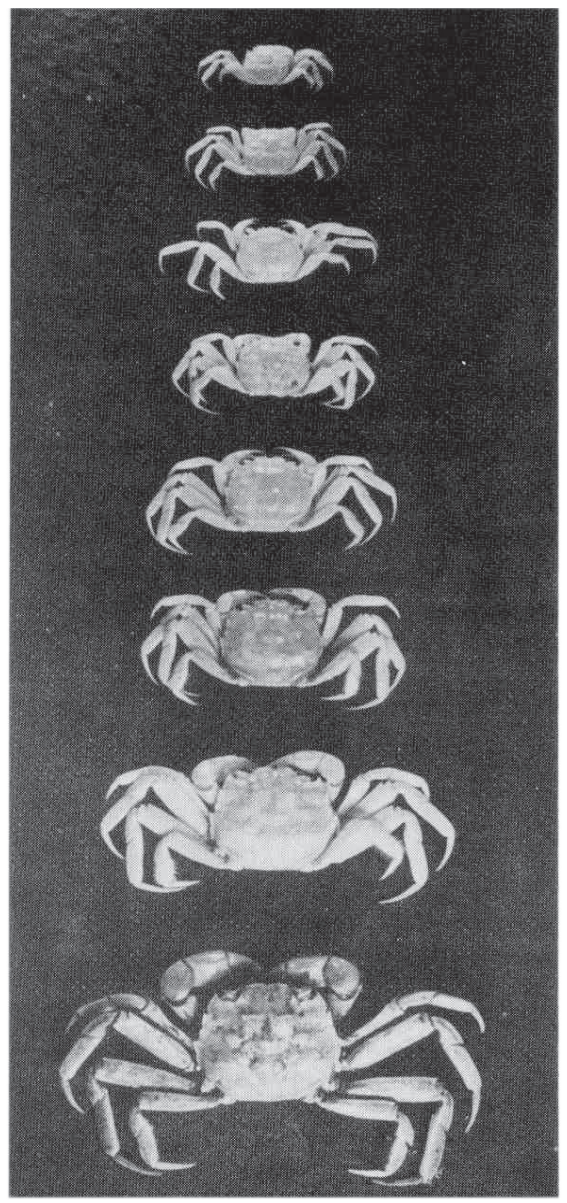

Figura 2. Crecimiento de un ejemplar de Cyrtograpsus angulatus (Boschi, 1971) . Registro del largo de caparazón ( $L$ ) de mudas sucesivas, al cabo de 300 días (de Lc: $7,8 \mathrm{~mm}$ a Lc: $29,3 \mathrm{~mm}$ ). Figure 2. Growth of a specimen of Cytograpsus angulatus (Boschi, 1971). Record of the carapace length $(L)$ of succesive molts after 300 days (from Lc: ${ }^{\mathrm{c}} 7,8 \mathrm{~mm}$ to Lc: $29,3 \mathrm{~mm}$ ). 
animales más longevos. Además se producen mudas relacionadas con el ciclo reproductivo de la especie, manifestándose cambios en las estructuras del cuerpo, en el tipo de sedas de los pleópodos (por ejemplo la expansión de las láminas tergo-laterales del pleon en los carideos o la presencia de sedas ovígeras para sujetar los huevos en la época de reproducción), sin variación en las dimensiones del cuerpo. Los procesos reproductivos tales como maduración gonadal y vitelogénesis modifican el ciclo de muda, como se ha demostrado para muchas especies (revisión en Adiyodi, 1985; Hartnoll, 1985). El crecimiento también está determinado por el sexo, por ejemplo, los machos en Caridea alcanzan mayor tamaño que las hembras, en cambio en Peneaoidea tienen, a igual edad, mayor talla las hembras. También se comprueba alometría en el tamaño de los quelípedos en un mismo individuo, cuyo ejemplo más notable se tiene en los machos de Uca.

El tipo de modificaciones como las indicadas anteriormente se ha comprobado mediante el estudio poblacional de $A$. longinaris en el que se relaciona la maduración gonadal con la duración del ciclo de muda y el crecimiento (Petriella y Bridi, 1992).

\section{Métodos de estudio de la edad y el crecimiento}

En los crustáceos la determinación de la edad ofrece serias dificultades, como se ha mencionado, en razón de que no existen estructuras duras permanentes que registren marcas indicadoras del crecimiento. Los procedimientos que más se prestan para el estudio de la edad en los crustáceos Decápodos se indican a continuacion, sobre la base de las ideas de Kurata (1962), Boschi (1971) y Hartnoll (1982), entre otros. Ninguno de los métodos brinda absoluta seguridad, por lo que es necesario realizar distintas verificaciones y comparaciones antes de tomar una decisión sobre la edad de la especie en estudio. A pesar de ello, toda la información que sea posible adelantar sobre el crecimiento de una especie, a veces de manera tentativa, puede servir de ayuda y guía para estudios posteriores. A continuación se indican brevemente las características de cada uno de estos métodos:

Examen de distribución de tallas modales (Método de Petersen). Se deben considerar numerosos factores para lograr una adecuada interpretación. Es necesario conocer aspectos fundamentales de la biología de la especie, en particular lo relativo a su reproducción y longevidad. Idealmente debería existir una sola época de reproducción anual y breve, con crecimiento significativo en cada año (para especies de vida larga) y las muestras deberían provenir de la misma población. Normalmente en este tipo de muestreos se pueden distinguir solamente las primeras clases de edad. Las clases mayores son más difíciles de detectar, debido al escaso incremento por muda y la mezcla que ocurre entre los individuos más viejos de distintas cohortes pero de igual talla, como ocurre por ejemplo con las especies de centollas del sur y norte de los océanos de ambos hemisferios, de los géneros Paralithodes, Lithodes, Paralomis, etc.

En las especies de vida breve, anual o bianual, como la mayoría de los peneidos y sergéstidos, el estudio del crecimiento se puede realizar mediante análisis de muestras periódicas (semanales/mensuales) de una misma población o stock en explotación, siguiendo el desplazamiento de los grupos modales a través del año. Este se conoce como método directo o de Petersen.

En la Argentina se han realizado estudios biológico-pesqueros del camarón A. longinaris y del langostino $P$. muelleri, en los que se estimó el crecimiento de estas especies mediante el mencionado procedimiento. Un ejemplo de ello son las investigaciones sobre el crecimiento del camarón de la región de Mar del Plata, empleando muestreos semanales de captura comercial de una misma embarcación de pesca costera que operaba en la región durante todo el año, estableciéndose las curvas de crecimiento, correspondientes a las cohortes en explotación de 1965, 1966 y 1967 (Boschi, 1969). También se determinó el crecimiento mediante el seguimiento de grupos modales del langostino de Bahía Blanca (Wyngaard y Bertuche, 1982) y existen algunos datos preliminares relativos al crecimiento del langostino del litoral patagónico (Boschi, 1989). Sobre el pequeño sergéstido Peisos petrunkevitchi del litoral marplatense, se ha estudiado el crecimiento mediante muestras mensuales obtenidas de las capturas, en las que se presentaba como fauna acompañante. En el año de estudio, 1981, a partir de marzo apareció una cohorte con una curva de distribución bien definida y posteriormente en el mes de agosto se incorporó otra cohorte con menor talla que la primera, evidenciándose mediante una curva netamente bimodal.

La primera cohorte luego del desove primaveral desaparece, quedando sólo el último grupo (Mallo y Boschi, 1982) (Fig. 3).

Marcación de animales en poblaciones naturales. Para que los resultados de las marcaciones 


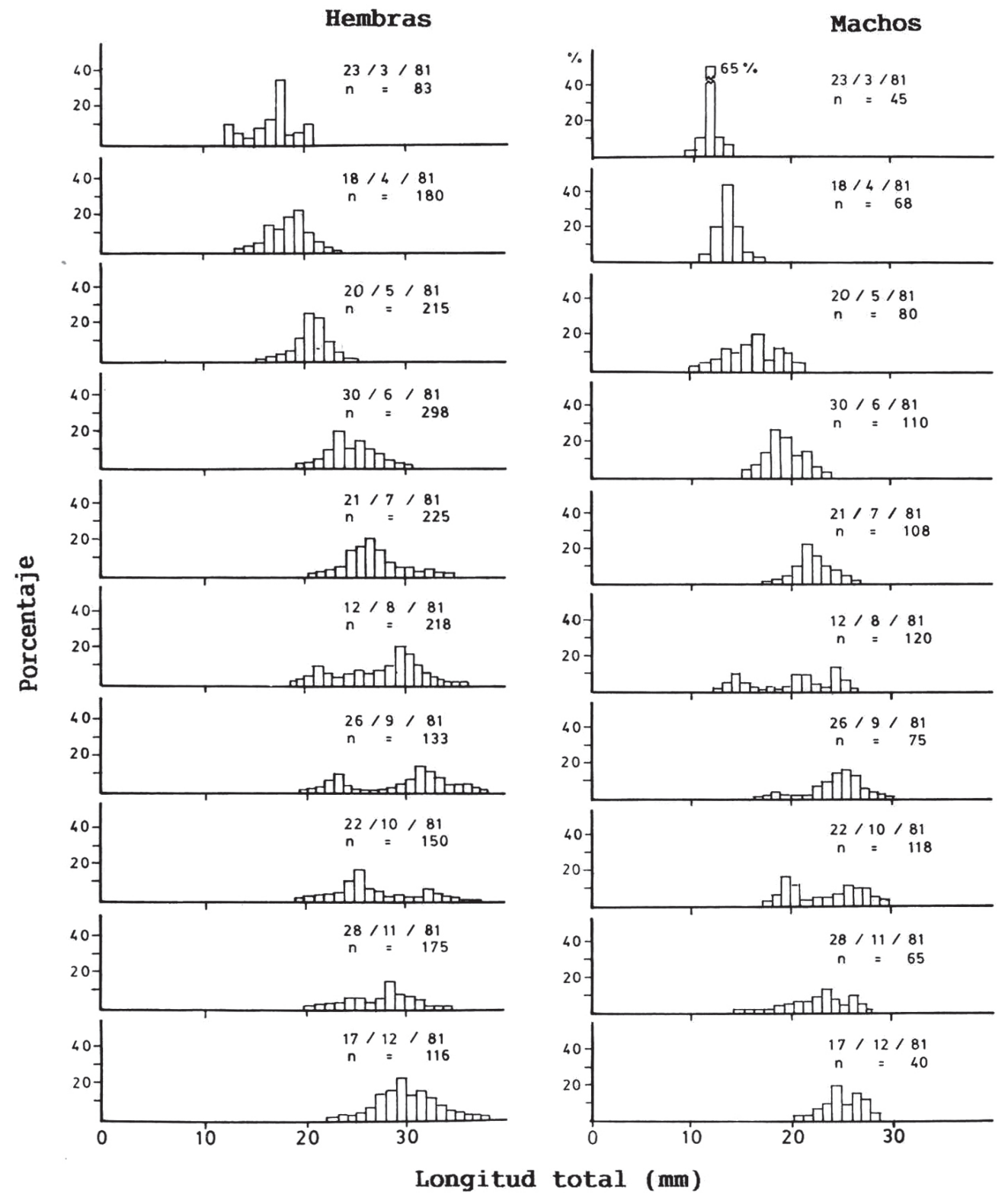

Figura 3. Distribución de tallas de Peisos petrunkevitchi de la región de Mar del Plata, según muestreos mensuales (Mallo y Boschi, 1982). Se comprueba la incorporación de otro grupo de edad a partir de agosto.

Figure 3. Length distribution of Peisos petrunkevitchi from the Mar del Plata region, from monthly samplings (Mallo and Boshi, 1982).

tengan valor para determinar el crecimiento, se deben cumplir los siguientes requisitos:

- $\quad$ La marca no debe desprenderse duranta la muda, para el caso de marcas que se sujetan al cuerpo. Ese problema no existe si la marcación se efectúa con colorantes vitales (me- nos útiles para el estudio de crecimiento individual).

El procedimiento de marcación y la marca misma no deben afectar el comportamiento ni la fisiología del animal. 
- Para conocer el tamaño o peso medio alcanzado por la población los ejemplares marcados deben distribuirse homogéneamente, conservando el mismo comportamiento y con igual probabilidad de ser recapturados.

- Asegurar la devolución de los animales marcados

A pesar de que todos las condiciones enumeradas difícilmente se cumplan en su totalidad, se han realizado numerosos trabajos a nivel mundial, empleando esta metodología con resultados variables pero en general satisfactorios (Lindner y Anderson, 1956; Dawson, 1957; Costello y Allen, 1961; Rounsefell, 1963; Costello, 1964; Klima, 1965; Boschi y Scelzo, 1971; Ruello, 1975; Marullo et al., 1976; Phillips et al., 1992; entre otros).

El método más simple consiste en el corte o perforación de alguna porción del tegumento, que permita el reconocimiento, luego de varias mudas y no se confunda con daños naturales. Se ha empleado con éxito en peneidos, cortando el extremo de uno o los dos urópodos con lo que se puede logran varias combinaciones.

También se han empleado marcas ferromagnéticas que se colocan debajo del exoesqueleto en la musculatura de la base de las patas o en el abdomen (Woodland, 1966; Ennis, 1972) previa inmersión de las mismas en una solución bactericida, para evitar infecciones. Se emplearon en especies de gran tamaño, sin resultados satisfactorios $\mathrm{y}$ es un procedimiento muy costoso ya que la marca debe reconocerse con un detector.

Un procedimiento usado en crustáceos decápodos de interés pesquero es fijar en el cuerpo del animal una marca externa, que generalmente consiste en un disco numerado, atravesando el caparazón y la musculatura con un alfiler al que se le dobla la punta para evitar que se desprenda. En estas condiciones la muda se realiza sin mayores dificultades. Otras marcas consisten en hilos, bandas vinílicas, etc. Por lo general en camarones se insertan en el primer somito abdominal, en cambio en cangrejos se las fija dorsalmente en el caparazón y en centollas en el istmo que une el abdomen con el pereion.

En poblaciones numerosas, con capturas de muchos miles de toneladas, como el caso de los camarones peneidos, con una amplia zona de distribución y distintos fondos de pesca, las marcaciones deben efectuarse en un elevado número de animales para que exista alguna probabilidad de recaptura. Por otra parte, la verificación de la recaptura es difícil debido al rit- mo de procesamiento del producto durante la navegación. De hecho estos procedimientos prácticamente no son empleados en el presente, aunque en muchos casos sería una forma irrefutable de conocer el crecimiento y los desplazamientos en toda el área de distribución de la especie, lo que permitiría determinar el grado de vinculación de las distintas cohortes en una región de pesca. El hallazgo de los ejemplares marcados en poblaciones de menor numerosidad se facilita por el procesamiento en laboratorio.

En la Argentina se efectuaron marcaciones en varias especies de crustáceos decápodos. En peneidos (A. longinaris y $P$. muelleri) de la región de pesca de Mar del Plata, se emplearon con buenos resultados discos numerados del tipo «Petersen», que se sujetan al animal mediante un alfiler de acero, del tipo usado para entomología, que atraviesa el primer somito abdominal (Boschi y Scelzo, 1971) (Fig. 4a). En el cangrejo Brachyura Ovalipes trimaculatus, en la misma región de Mar del Plata, también se utilizaron marcas consistentes en discos numerados, sujetos al animal mediante un hilo de nylon que atraviesa el costado del caparazón (Fenucci y Boschi, 1975). En estudios sobre el crecimiento y movimientos de la centolla del Canal Beagle, se llevó a cabo un programa de marcación, usando un espagueti de plástico amarillo y un disco tipo «Petersen» sujetos mediante un hilo del nailon a la estrecha región que une el abdomen con el cefalotórax. A pesar de que sólo se pudieron marcar unas 1.600 centollas de ambos sexos entre los años 1980-1982, se logró una excelente información sobre sus movimientos en el sector argentino del Canal Beagle su crecimiento individual (Boschi et al., 1984).

También se utilizó el colorante vital azul tripan, para la marcación de peneidos (langostino y camarón) de la zona de Mar del Plata, en los años 1968 y 1969. El colorante se inyecta en la arteria dorsal superior del camarón tiñiendo intensamente las branquias, lo que permite detectar al individuo marcado por la transparencia del branquiosteguito. El número de animales marcados en aquella época (incluyendo las marcas con discos y los teñidos) fue de 4168; la cantidad de recuperados fue baja, de apenas un $1 \%$, pero aceptable, teniendo en cuenta la numerosidad del stock de langostinos y camarones en explotación en esos momentos (Boschi y Scelzo, 1971) (Fig. 4b). 

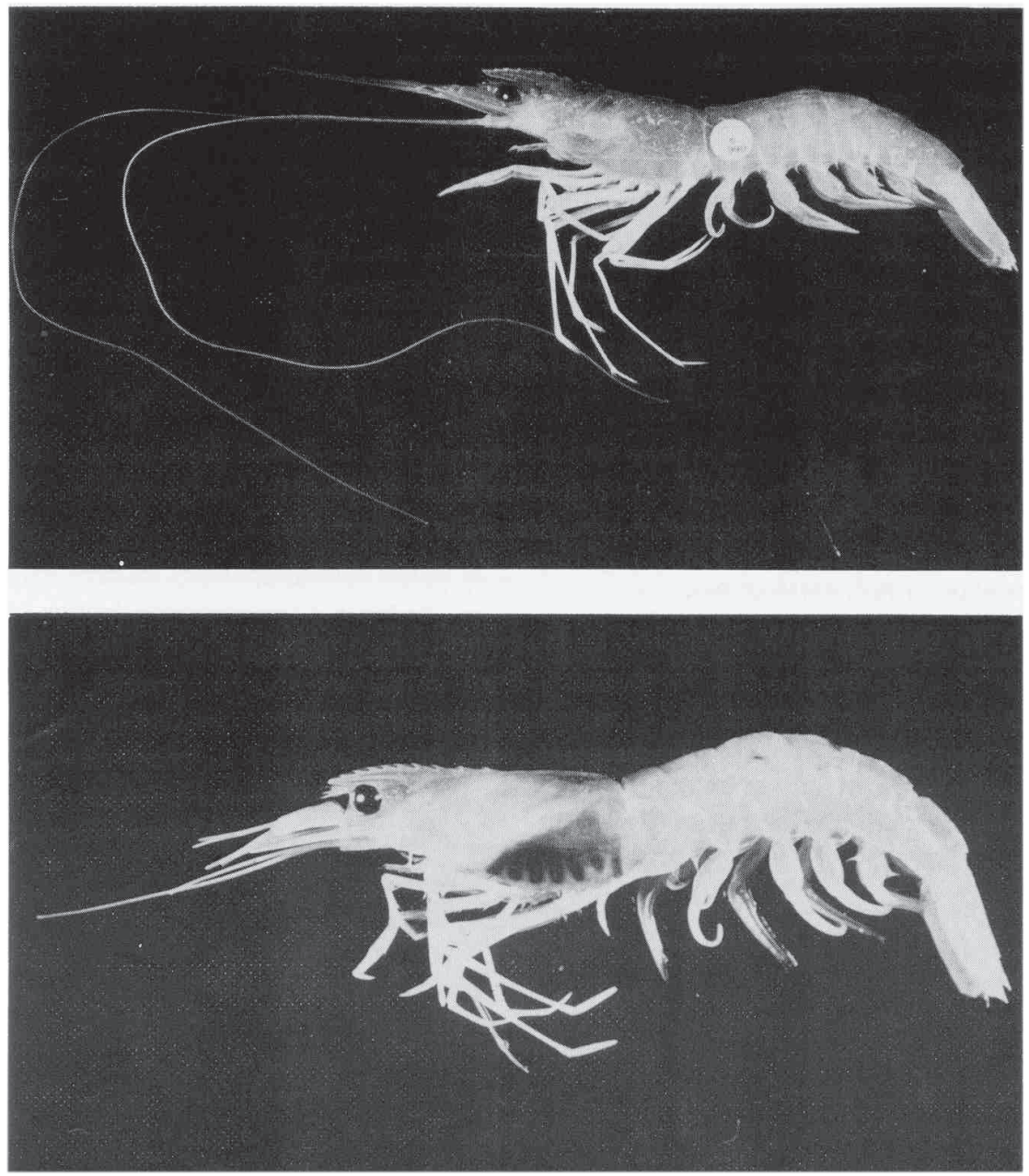

Figura 4. Diferentes tipos de marcas empleadas en estudios sobre crecimiento (Boshi y Scelzo, 1971): a) Marca tipo Petersen fijada al 1er somito abdominal, y b) Coloración vital con azul tripan, inyectado a nivel de las branquias.

Figure 4. Diferents types of taggs used in growth studies (Boshi y Scelzo, 1971): a) Petersen's type tagg attached to the 1rst abdominal somite, and b) Vital coloration with tripan blue, inyected at the gill level.

En condiciones experimentales se ha utilizado con éxito una marca de látex de aproximadamente 3 mm de lado adherida al cefalotórax de camarones y langostinos adultos con pegamento acrílico (Petriella, 1987).

Animales en cautividad. La única información disponible sobre la edad de muchas especies de crustáceos proviene de observaciones y estudios de animales en cautividad. Los resultados obtenidos de esta forma tienen muchas limitaciones y no es recomendable extraprolarlos a poblaciones naturales. Con animales criados en cautividad y originados de un mismo desove, se tiene la ventaja de saber con certeza el momento preciso de nacimiento. Durante los experimentos efectuados con el langostino $P$. muelleri y con el camarón A. longinaris en pequeños tanques de laboratorio, se observó que a las pocas semanas de desarrollo de las postlarvas y juveniles las tallas variaban significativamente, reduciéndose además diariamente el número de los mismos, por el acentuado canibalismo de los de mayor talla sobre los más pequeños en el momento de la muda.

En Mar del Plata, (Instituto de Biología Marina-INIDEP) se han efectuado numerosos ex- 
perimentos relativos al crecimiento de crustáceos decápodos mantenidos en condiciones de laboratorio. Se pueden mencionar los realizados con camarones (Boschi, 1969; Petriella, 1986), langostinos (Boschi, datos inéditos; Díaz y Petriella, 1988), y los cangrejos Pachycheles haigae y Chasmagnatus granulata (Boschi et al., 1967) y Cyrtograpsus angulatus (Boschi, 1971; Spivak, 1988). En varios casos se ha observado un retardo en el crecimiento, comparándolo con animales de ambientes naturales. En cambio, los experimentos de desarrollo larval y cultivo de postlarvas y juveniles del camarón $A$. longinaris demostraron un buen crecimiento en las primeras semanas de observaciones (Boschi y Scelzo, 1977 y datos inéditos) (Fig. 5).
Ultimamente se han llevado a cabo experimentos de desarrollo larval y cría masiva de postlarvas del langostino en Mar del Plata, en la Estación Experimental Nágera, con excelente crecimiento y una supervivencia del 60\% (Bridi y Fenucci, 1992; Galarza y Fenucci, 1992; Mallo et al., 1992).

Frecuencia de muda y tasa de crecimiento por muda. Conociendo el ritmo de muda en el tiempo, que naturalmente varía con la edad del individuo, y el incremento de peso o talla que se produce luego de cada ecdisis, se puede trazar la curva de crecimiento. Los resultados logrados en trabajos experimentales no siempre coinciden con la tasa de crecimiento de los animales de poblaciones naturales, pero reflejan en alguna medida la modalidad de crecimiento de la especie. A pesar de estas limitaciones, empleando su ajuste a diferentes modelos de regresión, se logran aceptables aproximaciones a la talla máxima alcanzada, es decir que el método tiene, en alguna medida, valor predictivo (Hiatt,1948; Tagatz, 1968; Hartnoll, 1982).

Estudios de este tipo se realizaron con la centolla del Canal Beagle, Lithodes santolla, particularmente considerando el aumento del largo del caparazón (Lc) en animales marcados y recapturados y el crecimiento experimentado en animales que mudaron en las trampas de pesca comercial. Teniendo en cuenta el incremento del largo del caparazón en machos de distintas tallas del Canal Beagle, sumándolos a datos publicados de la región de Magallanes (Chile) se pudo elaborar una matriz de crecimiento con los largos medios de premuda y los de postmuda, estimándose con ello una curva de máxima probabilidad de crecimiento (Boschi et al., 1984), si bien los datos de edad en aquel trabajo fueron estimativos y tampoco se dispuso de información sobre la relación entre el número de mudas y la edad. Según Vinuesa et al. (1992), los machos adultos mudan dos veces por año con tallas entre
Figura 5. Crecimiento de postlarvas de camarón Artemesia longinaris en cultivos experimentales: *individuos indiferenciados; $\mathbf{x}$ hembras; + machos.

Figure 5. Post-larvae growth of the shrimp Artemesia longinaris, in experimental cultures: *individuals non diferentiated; $\mathbf{x}$ females; + males.

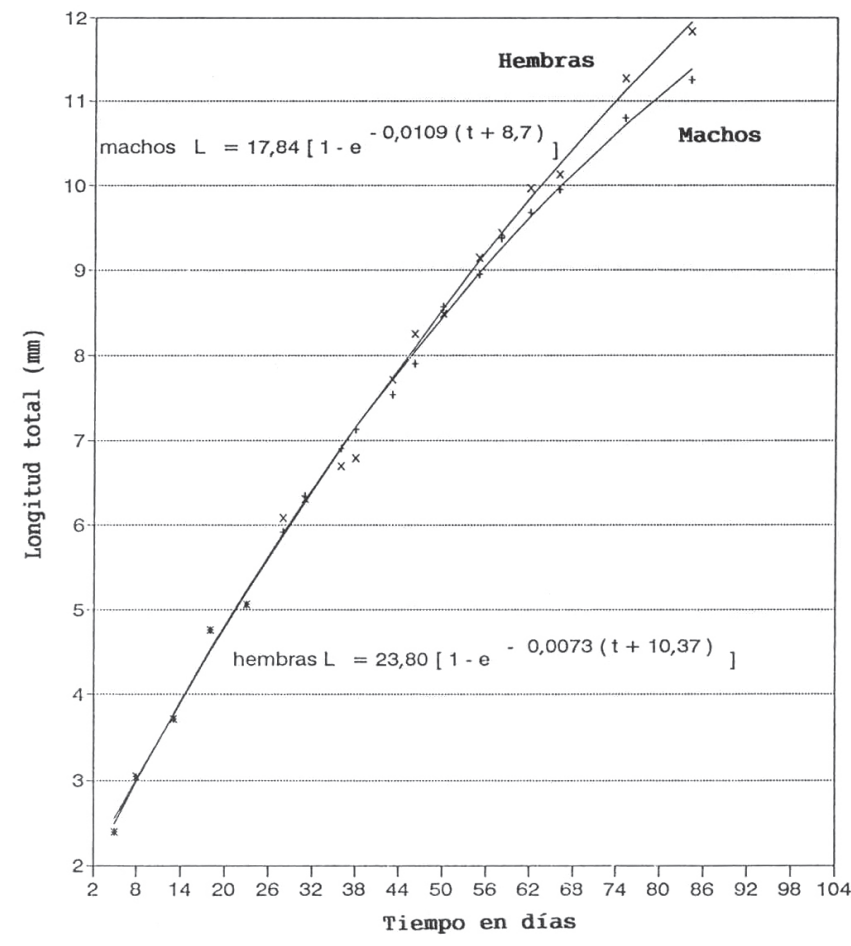


70-80 mm de Lc, luego una vez por año, hasta alcanzar la talla de 110-120 mm; posteriomente mudan cada dos años.

Un caso muy particular lo presenta el centollón Paralomis granulosa del Canal Beagle (Lovrich, 1991; Lovrich y Vinuesa, 1993, 1995). Su desarrollo embrionariodura entre 18 y 22 meses en la zona de estudio. La frecuencia de muda es menor que en la centolla, suponiéndose que esta especie muda una vez por año, en animales juveniles mayores de $35 \mathrm{~mm}$. Los machos maduran sexualmente a los $51 \mathrm{~mm}$ de Lc y las hembras a los $67 \mathrm{~mm}$. Las hembras adultas mudan cada dos años. Las mayores tallas estudiadas en esa región han sido de $88,8 \mathrm{~mm}$ de Lc para hembras y $115,5 \mathrm{Lc} \mathrm{mm}$ para machos. Esta es una especie de crecimiento lento y una larga vida.

La frecuencia de muda del camarón $A$. longinaris se ha determinado mediante estudios en laboratorio (Petriella, 1986), siendo de 17士3 días (a $19^{\circ} \mathrm{C}$ ), alargándose para individuos de mayor edad, según un modelo potencial positivo (Fig. 6).

En el caso del langostino $P$. muelleri, la frecuencia de muda es de $19 \pm 4$ días $\left(18,5-23,5^{\circ} \mathrm{C}\right)$, constatándose que a medida que se incrementa el peso premuda se alarga el período de intermuda, con ajuste a un modelo lineal (Díaz y Petriella, 1988) (Fig. 7).

De acuerdo con Burkenroad (1951) ninguno de los tres sistemas es enteramente satisfactorio, sugiriendo que el crecimiento se puede medir mediante el cálculo del promedio de mudas en la naturaleza y el incremento de talla por ecdisis. El porcentaje de mudas se puede establecer determinando el número de ejemplares con caparazón blando o por la frecuencia de mudas en acuario de animales recientemente capturados.

Marcadores bioquímicos. En los últimos años se han desarrollado técnicas que permiten estimar el crecimiento instantáneo de organismos acuáticos, por cuantificación de los ácidos nucleicos (Wright y Hetzel, 1985; Frantzis et al., 1992). Recientemente se han aplicado a especies de crustáceos como Penaeus vannamei (Moss, 1994a y 1994b) y Pacifastacus leniusculus (Edsman et al., 1994) con resultados promisorios, ya que es posible detectar las variaciones de la concentración de ARN o de la relación ARN/ADN producidas en 24 horas. Si estos resultados pueden cuantificarse experimentalmente, será posible estimar el crecimiento instantáneo a campo.

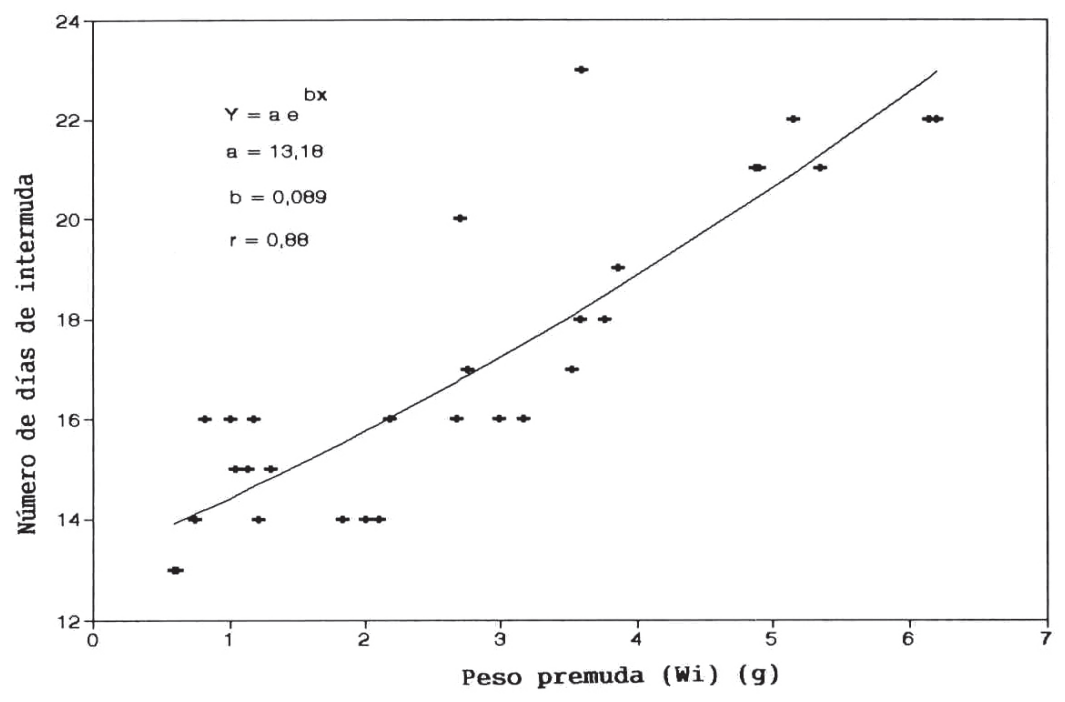

Figura 6. Relación entre el peso premuda $\left(W_{\mathbf{i}}\right)$ y el número de días de intermuda de Artemesia longinaris mantenidos en laboratorio (Petriella, 1986).

Figure 6. Relation between premolting $\left(\mathrm{W}_{\mathrm{i}}\right)$ and the number of intermolting days for Artemesia longinaris kept in the laboratory (Petriella, 1986). 


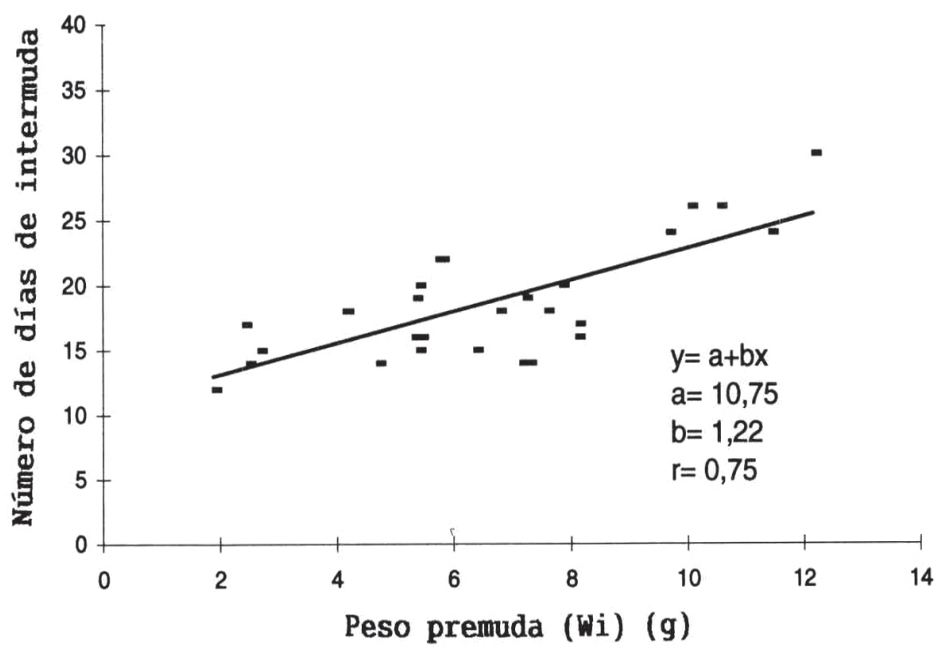

Figura 7. Relación entre el peso premuda $\left(\mathrm{W}_{\mathrm{i}}\right)$ y el número de días de intermuda de Pleoticus muelleri mantenidos en laboratorio (Díaz y Petriella, 1988).

Figure 7. Relation between the premolt weight $\left(\mathrm{W}_{\mathrm{i}}\right)$ and the number of intermolting days for Pleoticus muelleri kept in the laboratory (Díaz and Petriella, 1988).

Otro método que demuestra eficiencia es la determinación de la concentración de lipofucsina en el tejido nervioso, como índice de edad y crecimiento, con la ventaja que puede ser empleado con individuos salvajes o mantenidos en cautiverio (Sheehy, 1990a y 1990b; Sheehy et al., 1995).

Hasta el momento estas técnicas no se han aplicado en especies de crustáceos argentinos.

\section{Análisis cuantitativo del crecimiento}

Como quedó dicho, la discontinuidad del crecimiento de los crustáceos causa grandes dificultades para determinar las clases de edades. Fowler (1909) (en Kurata, 1962 y Botsford, 1985), en un estudio sobre ostrácodos estableció la primera expresión que describe este proceso:

$$
\ln \mathrm{L}=\ln \mathrm{b}+\mu^{*} \mathrm{~S}
$$

siendo $\mathrm{L}=$ longitud del cuerpo; $\mathrm{S}=$ estadío; $\mathrm{y}$, a y $\mathrm{b}=$ constantes

Para analizar el crecimiento y la frecuencia de muda en crustáceos, pueden emplearse, como se ha mencionado, animales en cautividad, determinando la diferencia entre la variable analizada (peso o talla) antes y después de la muda.

Hiatt (1948) para describir el crecimiento del cangrejo Pachygrapsus crassipes, empleó un diagrama representando en la abscisa la longitud premuda y en la ordenada la longitud postmuda, obteniendo una línea recta. Posteriormente Kurata (1962) aplicó el método gráfico de Hiatt para analizar el crecimiento de otros grupos de crustáceos, determinando una ecuación de regresión simple para longitud total y peso:

$$
\mathrm{L}_{\mathrm{n}+1}=\mathrm{a}+\mathrm{b}^{*} \mathrm{~L}_{\mathrm{n}}
$$

siendo L y L las dimensiones antes y después de la muda $\mathrm{y}$ a $\mathrm{y}^{\mathrm{n}} \mathrm{b}$ constantes.

De acuerdo al valor de $b$ (coeficiente de crecimiento), el tipo de crecimiento queda definido como:

crecimiento geométrico progresivo: $\mathrm{b}>1$

crecimiento geométrico regresivo: $b<1$

crecimiento aritmético: $\quad \mathrm{b}=1$

El coeficiente b es empírico; para dimensiones lineales varía generalmente entre 0,8 y 1,4 y es mayor en los jóvenes que en los adultos.

Con fines prácticos, Kurata (1962) adoptó los siguientes valores:

crecimiento geométrico progresivo: $\mathrm{b}>1,05$

crecimiento geométrico regresivo: $\quad 1,05^{3} \mathrm{~b}^{3} 0,95$

crecimiento aritmético: $\quad b<0,95$

Este modelo fue modificado por Mauchline (1976; 1977) que propone una aproximación alter- 
nativa, empleando el porcentaje de longitud pre y postmuda. Este factor de crecimiento es mudable a lo largo de la vida del animal y se manifiesta muy variable en las etapas de postlarva, juvenil y subadulto, en cambio generalmente es constante en los adultos, llegándose asintóticamente al peso o largo máximo. En algunos casos ese factor se modifica cuando el animal llega a la muda de pubertad, momento en que se produce un cambio en el crecimiento relativo del animal, que coincide con la madurez sexual y también con las profundas modificaciones que se perciben en el paso de larva-megalopa-juvenil, por lo que se sugiere que el análisis del crecimiento debe efectuarse para cada etapa del ciclo de vida (Hartnoll, 1982).

Se dispone de menos información en cuanto al análisis de la duración del período de intermuda, ya que implica mayores dificultades metodológicas y es difícil de realizar en el campo con animales marcados. Generalmente se estudia en el laboratorio, con las limitaciones debidas al confinamiento, si no se conocen y controlan adecuadamente las variables ambientales que modifican la duración de este período. Botsford (1985) presentó una revisión detallada de los trabajos realizados con este enfoque.

Dentro de las expresiones matemáticas que tratan de describir el crecimiento en organismos marinos, la de von Bertalanffy (1938), es una de las que mejor se ajusta a los procesos biólogicos y está dada por la siguiente ecuación:

cuya solución es:

$$
\mathrm{dl} / \mathrm{dt}=\mathrm{K}\left(\mathrm{L}_{\infty}-1\right)
$$

$$
\mathrm{L}_{\mathrm{t}}=\mathrm{L}_{\infty}\left\{1-\mathrm{e}^{-\mathrm{K}\left(\mathrm{t}-\mathrm{t}_{0}\right)}\right.
$$

donde:

t = edad del crustáceo

$\mathrm{L}$ = longitud del crustáceo a la edad $\mathrm{t}$

$\mathrm{K}=$ coeficiente de crecimiento

$\mathrm{L}_{\infty}=$ longitud asintótica

$\mathrm{t}$ = edad que hipotéticamente debe tener el crustá-

0 ceo para que su largo sea igual a cero.

La edad cero en crustáceos, para estudios del crecimiento, se toma normalmente cuando finaliza el desarrollo larval y se inicia la primera postlarva en peneidos y carideos, el primer cangrejo en braquiuros o la talla de asentamiento en puerulus de langostas, etc.

Debido al crecimiento discontinuo de los crustáceos este modelo se ajusta mas adecuadamente para especies de crecimiento rápido como peneidos y sergéstidos.

Las curvas de crecimiento obtenidas se ajustan al modelo de Bertalanffy pero en realidad se pueden alejar considerablemente del valor medio de crecimiento de la especie y ello se debe a la pronunciada variación del crecimiento individual ya que se ha determinado que animales de una misma edad tienen tallas y pesos distintos, en razón de las condiciones ambientales y disponibilidad de alimento de cada región u otros factores.

En el estudio del crecimiento en poblaciones del camarón $A$. longinaris, del langostino $P$. muelleri y del camaroncito $P$. petrunkevitchi se ha empleado con buenos resultados este modelo. Boschi (1969a y 1969b) estudió el crecimiento del camarón de la región de pesca de Mar del Plata, empleando el método de Petersen, mediante muestreos al azar en una misma área de pesca; igual procedimiento se ha seguido para el langostino y el camaroncito, como se mencionó anteriormente (Figs. 8 y 9).

\section{Incremento por muda}

El incremento por muda es el que se percibe en el aumento de talla, peso o volumen que ocurre entre un estadío larval y el siguiente o entre mudas sucesivas del juvenil o adulto. El crecimiento absoluto se comprueba por las modificaciones que comprende la totalidad del cuerpo, en cambio el crecimiento relativo se manifiesta por las variaciones ocurridas en ciertas partes del cuerpo comparándolas con otras.

El crecimiento por muda depende fundamentalmente de la edad de los individuos y de las condiciones ambientales. Por lo general en las etapas postlarval y juvenil las especies muestran mayor frecuencia de muda y un crecimiento más rápido, disminuyendo el porcentaje de incremento por muda con la edad. Un ejemplo lo constituye la centolla $L$. santolla del Canal Beagle, que tiene entre seis y siete mudas en el primer año de vida, con un factor de crecimiento medio de $26 \%$. En el tercer año, muda dos o tres veces, pero el porcentaje de incremento va disminuyendo. Las hembras siguen mudando una sola vez por año y los machos más grandes mudan una vez cada dos años (Vinuesa et al., 1990). El crecimiento por muda de Lc es de unos 


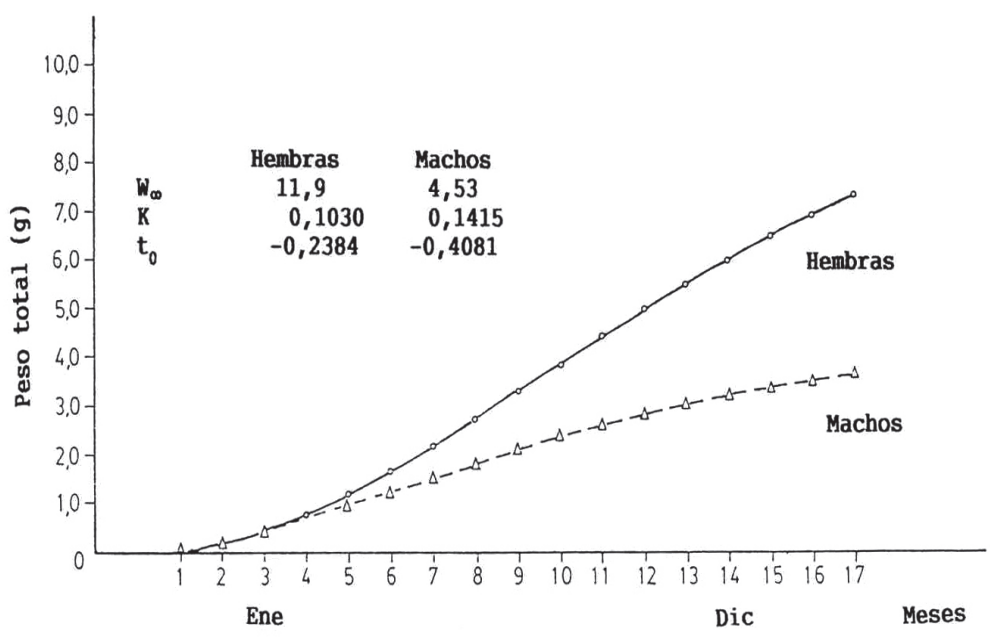

Figura 8. Curva de crecimiento en peso de Artemesia longinaris en la región de Mar del Plata (muestreos mensuales).

Figure 8. Weigth growth curve for Artemesia longinaris in the Mar del Plata region (monthly sampling).

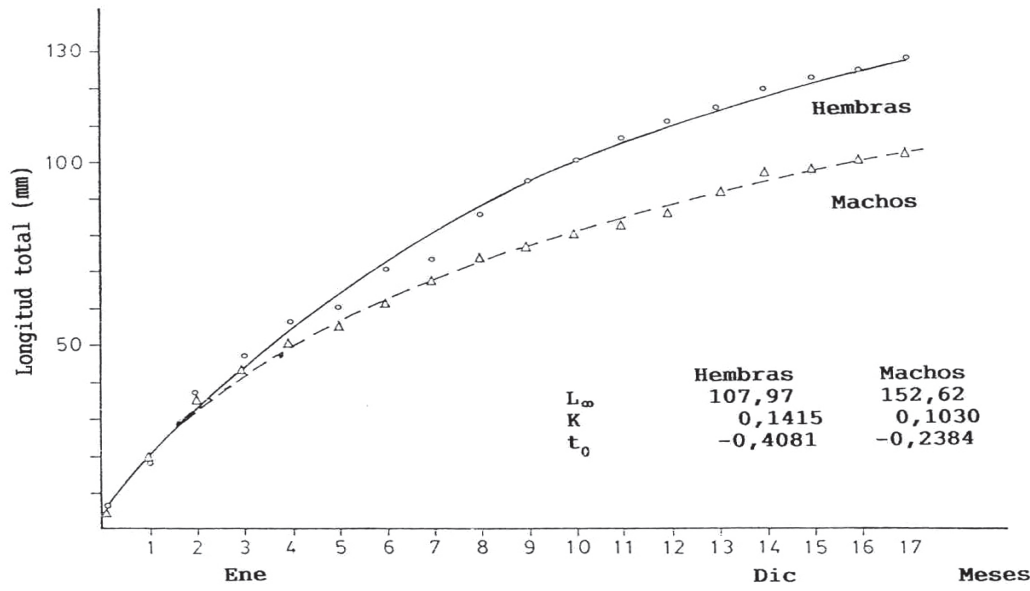

Figura 9. Curva de crecimiento en largo de Artemesia longinaris en la región de Mar del Plata (muestreos mensuales)

Figure 9. Length growth curve for Artemesia longinaris in the Mar del Plata region (monthly sampling). 
siete $\mathrm{mm}$ en los juveniles y oscila entre 4 y $6 \mathrm{~mm}$ en las hembras adultas y entre 10 y $15 \mathrm{~mm}$ en los machos adultos (Boschi et al., 1984; Vinuesa et al., 1990).

\section{Relación del crecimiento con la talla}

$\mathrm{Al}$ comienzo de los estudios sobre crecimiento en los crustáceos decápodos prevaleció el concepto de que la proporción de crecimiento era constante durante toda la vida del animal luego de cada muda. Con las primeras observaciones experimentales se comprobó que la tasa de crecimiento decrece con la edad. Estos conceptos pueden generalizarse para la mayoría de los decápodos, desde el comienzo de las postlarvas y primeros juveniles hasta los adultos.

Se han efectuado observaciones sobre los aspectos mencionados en la Argentina con varias especies de interés comercial, particularmente en langostino, camarón, centolla y centollón (Angelescu y Boschi, 1959; Boschi, 1969a y 1969b; Boschi et al., 1984, Vinuesa et al., 1990; Lovrich, 1991). Asimismo, en estudios sobre el langostino y camarón mantenidos en laboratorio (Petriella, 1986; Díaz y Petriella, 1988) se ha determinado el crecimiento en largo como geométrico regresivo $(b=0,95$ y 0,94 , respectivamente), es decir que el incremento en talla post-muda decrece con el tamaño inicial (Figs. 10 y 11).

Por otra parte Boschi (1971) analizando el crecimiento y mudas de Cyrtograpsus angulatus, en condiciones de laboratorio, determinó que un cangrejo macho, luego de 299 días, mudó ocho veces y desde la talla inicial de 7,8 llegó a 29,3 mm de Lc (Fig. 2), pero destaca que cangrejos de la misma especie en colectores ubicados en la zona portuaria llegaron a igual talla en 150 días. Spivak (1988) estudiando la muda y crecimiento de la misma especie, estableció una disminución del porcentaje de incremento de talla en cada muda, con el aumento de tamaño, en hembras de 4,0 a 6,9 mm de Lc, con un porcentaje promedio de incremento por muda de $22,40 \pm 3,9$, hasta animales entre 16,0 y $18,9 \mathrm{~mm}$ de Lc, con un porcentaje promedio de 17,99 $\pm 3,6$ $\%$ y para machos entre $24,1 \pm 3,6$ y $16,1 \pm 2,7$ con ejemplares de igual intervalo de tallas.

\section{Dimorfismo y maduración sexual}

Entre los factores internos que modifican la frecuencia de muda, quizá el más importante sea el estado de maduración sexual. Varios autores han comprobado que antes de la madurez el tiempo entre mudas sucesivas es casi igual para machos y hembras, tal como se comprobó para el camarón $A$. longinaris, trabajando con subadultos y adultos inmaduros de ambos sexos (peso inicial: 0,60-6,20 g) (Petriella, 1986). Por otra parte, estudiando el ciclo de muda de la población natural de esta especie Petriella y Bridi (1992) encontraron variaciones en la duración de la intermuda, asociadas a la época de reproducción. En los meses en que las hembras alcanzan el máximo grado de maduración ovárica (agosto-septiembre) la mayoría (65\%) se encuentra en premuda, mientras que la frecuencia de postmuda es baja (5-10\%). Luego del desove (octubre) se determinó una marcada disminución de individuos en premuda (tanto machos como hembras) y un aumento de ejemplares en postmuda (Fig. 12). En el langostino P. muelleri sólo se dispone de datos experimentales (Díaz y Petriella, 1988). Con individuos inmaduros de peso inicial entre 1,9 y 12,1 g, no se encontró una diferencia estadísticamente significativa entre machos y hembras (Fig. 11).

Por otra parte, muchas especies de crustáceos decápodos, cuando llegan a la madurez sexual presentan cambios morfológicos importantes, especialmente los Caridea y otros grupos que llevan los huevos sujetos a los pleópodos. Algunos son de carácter permanente y otros transitorios, ligados al ciclo reproductivo, particularmente al transporte de los huevos en la «cámara incubadora» de la hembra, que consiste en modificaciones de algunas estructuras de los apéndices, presencia de sedas ovígeras, etc. (Boschi, 1963).

Los caracteres sexuales secundarios que distinguen los machos de las hembras, en Caridea, en general se pueden agrupar de la siguiente manera, de acuerdo con Hoglund (1943) y Boschi (1963). Caracteres sexuales permanentes

Consisten en la presencia del appendix masculino en el segundo par de pleópodos del macho. Estucturas del quinto par de periópodos y tamaño distinto de las placas esternales de los somitos XII y XIII en machos y hembras; mayor crecimiento del segundo par de periópodos en los machos. Mayor tamaño de las placas tergolaterales de los somitos del abdomen de la hembras, así como mayor desarrollo de los precoxoditos de los pleópodos de éstas.

Caracteres sexuales periódicos

Se observan sedas ovígeras, no pectinadas, en el basipodito de los pleópodos 1 al 4 de la hembra, destinadas a sujetar los huevos durante el desarrollo embrionario. Aparecen con la muda que sigue 
a la fecundación y desaparecen con la muda final luego del último desove, en las especies de climas templados. Pleópodos con sedas suplementarias plumosas, blandas y pectinadas en la época de reproducción que desempeñan la función de mantener la «camara incubadora» protegida y cerrada.

El crecimiento y el ciclo de muda se ven también afectados durante el período de reproducción de la hembra que lleva los huevos adheridos a los pleópodos. Durante ese lapso no ocurre el cambio del exoesqueleto. En los Caridea el desarrollo embrionario varía entre una semana hasta cerca de dos meses, pero en el caso de los litódidos, este proceso puede demandar unos 290 días, como en la centolla L. santolla del Canal Beagle y en el centollón $P$. granulosa cerca de dos años, como se ha mencionado anteriormente.

Por otra parte, la muda reproductiva de los carideos no involucra necesariamente crecimiento, sino tiene que ver con el período de desarrollo embrionario y las veces que este sucede en el año. Las especies de mares fríos suelen tener una sola reproducción anual, las de las zonas templadas dos por año y en las de climas tropicales la reproducción es continua.

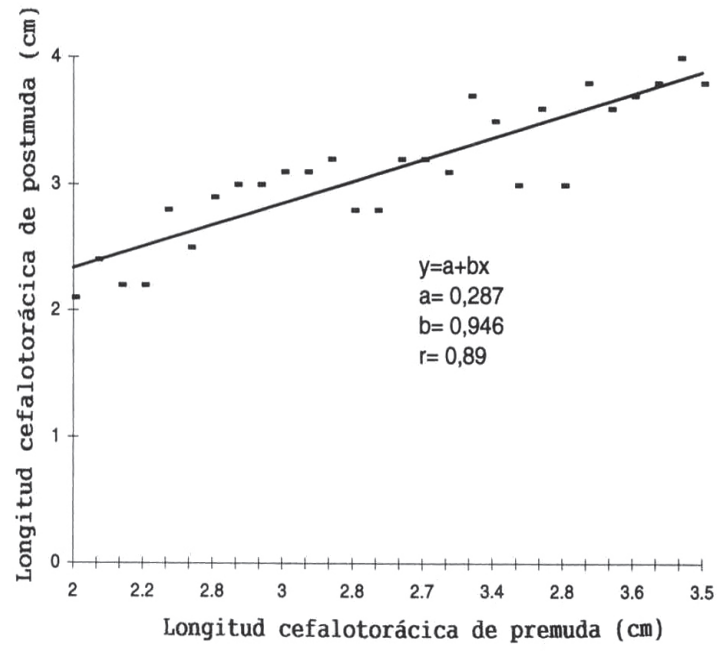

Figura 10. Crecimiento del langostino Pleoticus muelleri en laboratorio (Díaz y Petriella, 1988). Relación entre el largo del cefalotórax premuda (Lci) y el largo del cefalotórax postmuda (Lcf).

Figure 10. Growth of the shrimp Pleoticus muelleri in the laboratory (Díaz and Petriella, 1988). Relationship between the premolting cephalothoraxic length (Lci) and the postmolting cephalothoraxic length (Lcf).

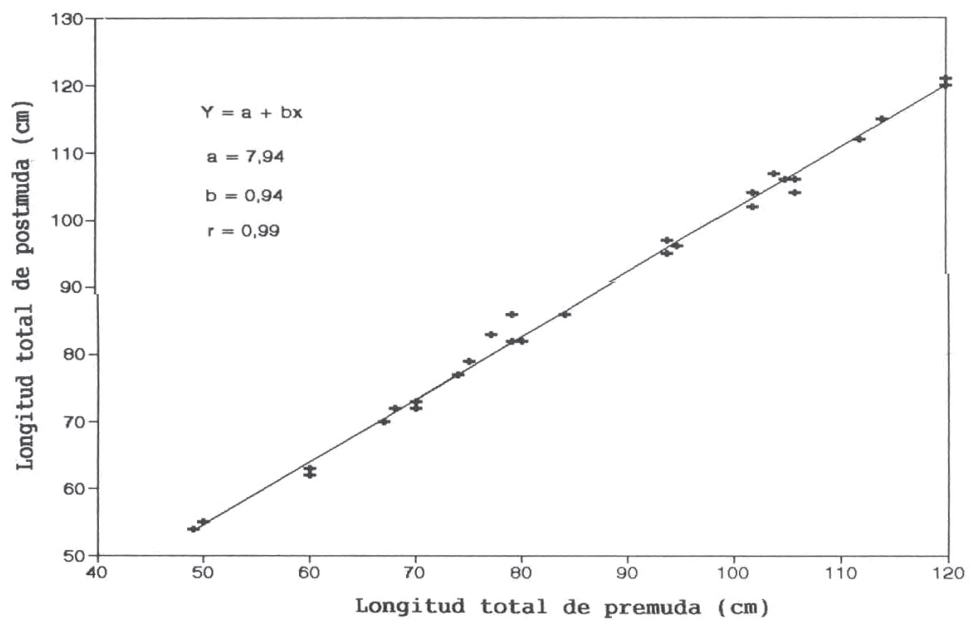

Figura 11. Crecimiento del camarón Artemesia longinaris en laboratorio (Petriella, 1986). Relación entre el largo total premuda $\left(L_{i}\right)$ y el largo total postmuda $\left(L_{t}\right)$.

Figure 11. Growth of the shrimp Artemesia longinaris in the laboratory (Petrilla, 1986). Relationship between the total premolting length $\left(\mathrm{L}_{\mathrm{i}}\right)$ and the postmolting total length $\left(\mathrm{L}_{\mathrm{t}}\right)$. 

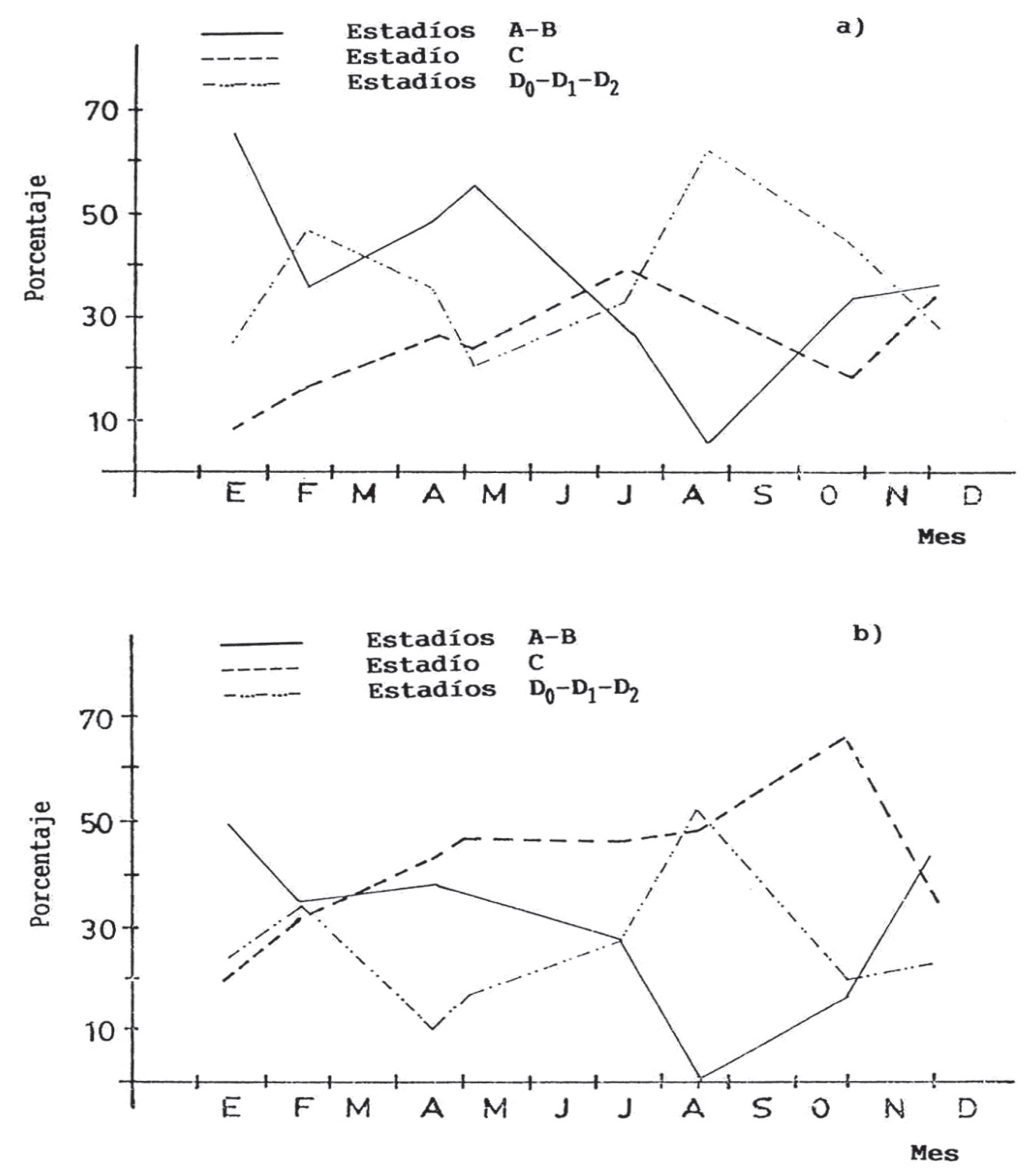

Figura 12. Variación de la frecuencia de estadíos del ciclo de muda de la población de Artemesia longinaris (Petriella y Bridi, 1992). (a) hembras; (b) machos, estadíos A-B: postmuda; C: intermuda; $D_{0}{ }^{-} D_{2}$ : premuda. Figure 12. Frequency variation of the molting cycle stages of the Artemesia longinaris population (Petriella and Bridi, 1992). (a) females; (b) males, stages A-B: postmolting; C: intermolting; $D_{0}{ }^{-} D_{2}$ : premolting.

\section{Influencia de las características ambientales sobre el crecimiento}

\section{Temperatura}

Numerosas observaciones permiten concluir que uno de los principales factores que afecta al crecimiento es la temperatura, si bien sus efectos son variables y tienen influencia sobre el metabolismo en general.

López y Fenucci (1988) determinaron que el camarón A. longinaris tiene mayor crecimiento entre los $15-19^{\circ} \mathrm{C}$ que entre $24-26^{\circ} \mathrm{C}$. Una repuesta similar obtuvieron Harán et al. (1992) trabajando con el langostino $P$. muelleri. Los ejemplares mantenidos entre los $14-16^{\circ} \mathrm{C}$ crecieron más que los mantenidos a temperaturas entre $8-10^{\circ} \mathrm{C}$ y $26-27^{\circ} \mathrm{C}$. Este efecto se debería a otra respuesta asociada a un aumento del metabolismo: el acortamiento de la intermuda, que modifica el ritmo de movilización de reservas, no permitiendo verdadero crecimiento.

La variación de la frecuencia de muda relacionada con los cambios de la temperatura fueron determinados para el camarón (Petriella y Bridi, 1992) de acuerdo a lo siguiente: mientras las temperaturas son altas (alrededor de $20^{\circ} \mathrm{C}$ ) la intermuda es breve y la premuda es corta. Cuando la temperatura del agua des- 
ciende (otoño), la intermuda se alarga. En primavera, se acortan la intermuda y premuda, aumentando el ritmo de muda, que se refleja en un mayor número de individuos en postmuda. Debido a que las fluctuaciones anuales de la temperatura de las aguas de Mar del Plata son del orden de los $13^{\circ} \mathrm{C}$, éste sería el factor regulador de la periodicidad de la ecdisis y el crecimiento, modificando el efecto causado por el tamaño, excepto en la época de maduración gonadal, como ya se mencionó (Fig. 13).

Luz

La luz tiene una decisiva influencia sobre el comportamiento de los crustáceos, especialmente aquellos que viven en aguas oceánicas, y en particular en cuanto a la mayor actividad que desarrollan algunas especies de peneidos durante las horas de reducida luminosidad o nocturnas y en mares costeros turbios con poca transparencia de las aguas. Por esta razón en muchas regiones tropicales y subtropicales del Caribe, con mares transparentes, varias especies de peneidos se pescan comercialmente en horas nocturnas, como Penaeus aztecus, $P$. duorarum, etc. En cam-

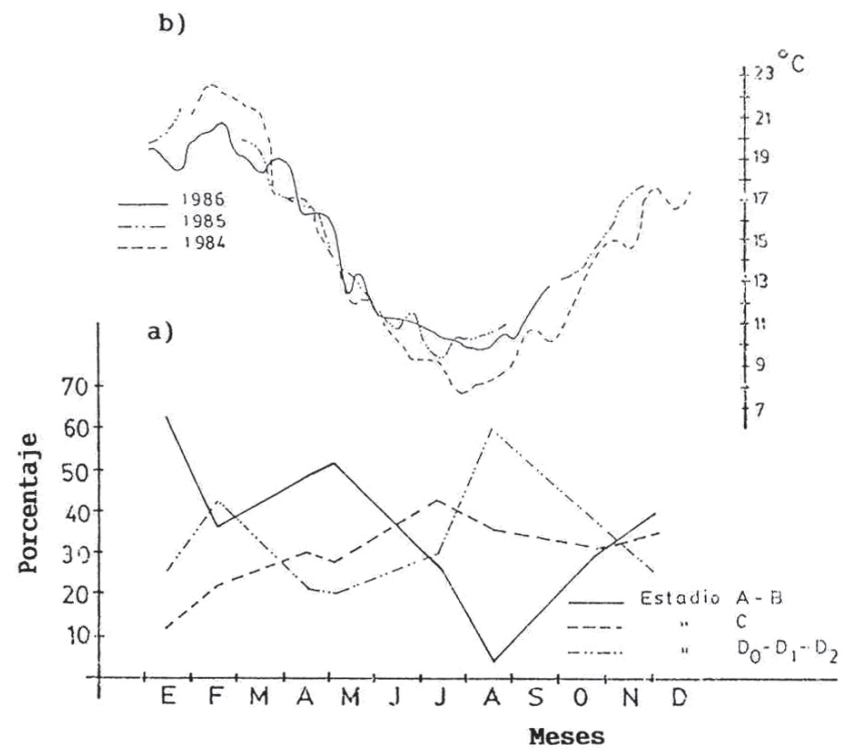

Figura 13. Variación de la frecuencia de estadíos del ciclo de muda de la población de Artemesia longinaris (Petriella y Bridi, 1992). a) totales de machos y hembras, estadíos A-B: postmuda; $C$ : intermuda; $D_{0}-D_{2}$ : premuda, $y$ b) temperatura.

Figure 13. Frequency variation of the molting cycle stages of the Artemesia longinaris population (Petriella and Bridi, 1992). a) totals males and females, stagesA-B: postmolting; C: intermolting; $D_{0}-D_{2}$ : premolting, and b) temperature bio en horas de mayor luminosidad, los individuos se refugian enterrándose en el fondo fangoso o arenoso, quedando prácticamente inactivos.

En el litoral de Argentina tanto el camarón como el langostino tienen el hábito de enterrarse en el sustrato. Los efectos de este comportamiento sobre la pesca son relativos, debido a la profundidad de capturas de estas especies, que suele ser superior de los 30-40 m y hasta 70-80 m en el golfo San Jorge, como se comprobó para el langostino. En la costa de Mar del Plata con aguas generalmente agitadas y cargadas de sedimentos, la pesca si bien comienza a la madrugada continua durante toda la mañana. Sin embargo, los pescadores saben que si se prolonga el buen tiempo y las aguas se mantienen transparentes, las mejores capturas se realizan en horas de la madrugada.

En cuanto a los efectos de la luz sobre el ciclo de muda, no existe demasiada información al respecto, pero se ha demostrado, para varias especies y especialmente para Peneidos que tanto la intensidad como la duración del fotoperíodo actúan modificando la frecuencia de la ecdisis y afectando al crecimiento (Dalley, 1980; Chamberlain y Lawrence, 1981). Para A. longinaris se ha determinado que fotofases claras de 10 o mas horas favorecen la muda y el crecimiento, mientras que ciclos de 14 o mas horas de oscuridad inhiben la ecdisis sin modificar la supervivencia (Petriella, en prensa).

\section{Salinidad}

Este factor tiene decidido efecto sobre las especies estuarinas o que habitan lagunas costeras de aguas salobres, con marcadas oscilaciones estacionales de la salinidad por lluvias, sequías o ingreso de agua oceánica. Las especies migradoras entre aguas continentales y el mar, están adaptadas a soportar pronunciados cambios de salinidad, por lo que desarrollan mecanismos eficientes de osmoregulación. Los cambios de salinidad pueden alterar significativamente el comportamiento de los crustáceos Decápodos, pero también en este aspecto se dispone de pocos resultados.

Harán et al. (1992) determinaron para A. longinaris mayor crecimiento para salinidades entre 25 y $31 \%$; ; a menor salinidad (16\%o) obtuvieron muy bajo in- 
cremento en peso. Los mismos autores obtuvieron resultados similares trabajando con el langostino $P$. muelleri.

\section{Contaminación}

Existen muchos casos donde se ha detectado la influencia negativa para el crecimiento y supervivencia de crustáceos, por acción de contaminantes, particularmente pesticidas, plaguicidas y otros compuestos químicos, derivados del petróleo. La respuesta más común de los crustáceos expuestos a poluentes no metálicos es la inhibición de la ecdisis y el aumento de la duración del desarrollo (Fingerman, 1985). Lombardo et al. (1982) probando los efectos de los pesticidas etil parathion y DDVP sobre larvas de la centolla L. antarcticus, si bien no analizaron el crecimiento, encontraron alta mortalidad a bajas concentraciones.

Esta es una línea de trabajo que recién se inicia para las especies del mar argentino y que deberá profundizarse con un enfoque experimental, que permita aclarar las interacciones entre los contaminantes, los factores ambientales y los biológicos.

\section{Otros factores que afectan al crecimiento}

\section{Nutrición}

Los crustáceos decápodos en su medio natural tienen requerimentos alimenticios bastante específicos y no se han encontrado demasiados casos de especies oportunistas. Las áreas de alimentación son fijas así como el ritmo de alimentación. Las mayores dificultades en los cultivos, se hallan en lograr una dieta apta que permita un crecimiento normal o superior al del ambiente. En el presente sigue siendo un desafío la preparación de un alimento óptimo para especies de decápodos utilizadas en cultivos masivos.

Mediante estudios de laboratorio y a escala de planta piloto se han preparado dietas con muy buenos resultados sobre el crecimiento y la maduración de camarón y langostino de la Argentina. Para ambas especies los porcentajes de proteínas y lípidos varían entre 40-48\% y 6-8\%, respectivamente (Fenucci et al., 1981, 1983; Petriella et al., 1984; Muller et al., 1986).

Influencia de pérdida y regeneración de apéndices

La presencia de crustáceos con un número incompleto de apéndices es frecuente en la naturaleza, fácilmente observable en especies de Brachyura intermareales que muestran la falta de más de un pereiópodo, desarrollando una actividad aparentemente normal. Ello se debe al fenómeno de autotomía mediante el cual el cangrejo pierde parte de su miembro. Ocurre en un sólo plano de fractura, ubicado cerca de la base del apéndice entre el basipodito con el isquiopodito (McVean, 1982). Lo más singular de esto, es que el individuo puede reestablecer ese apéndice por un proceso de regeneración que se cumple durante varios ciclos de muda, hecho poco frecuente en otros grupos animales (Skinner, 1985).

No están definidas las consecuencias de la pérdida de un apéndice y su regeneración sobre el crecimiento de los crustáceos. Se ha establecido (Hopkins, 1985) que la autotomía y regeneración de patas o quelípedos en machos de Uca pugilator perturba o inhibe el crecimiento normal, mientras que las estructuras regeneradas muestran una restauración acelerada, aunque también se puede alterar el crecimiento alométrico de todo el animal en el transcurso de varias mudas.

Los efectos de este fenómeno sobre la muda y el crecimiento son variables. Por un lado se puede producir una mayor frecuencia de mudas, pero sin crecimiento, como se verificó con Cyrtograpsus angulatus (Spivak, 1990). Por otra parte la incidencia de cangrejos que evidencian falta de apéndices en poblaciones naturales ha sido señalada como muy alta en varios grupos de Decápoda (McVean, 1982). Spivak y Politis (1989) examinaron 2243 cangrejos de la mencionada especie de grápsido de la laguna Mar Chiquita (Provincia de Buenos Aires, Argentina) hallando que el mayor porcentaje de animales con autotomía se produce, en ambos sexos, en cangrejos adultos entre 25 y $30 \mathrm{~mm}$ de ancho de caparazón, con un valor medio de $86 \%$; en los especimenes pequeños se determinó poca incidencia de autotomía. Todo ello llama poderosamente la atención ya que no hay respuestas concretas a los interrogantes de por qué ocurre con tanta frecuencia en algunos grupos como en Brachyura.

\section{Parasitismo}

Existen antecedentes de que el parasitismo puede reducir el crecimiento o detenerlo totalmente. También los parásitos que afectan las gónadas inhiben al animal para cumplir con el ciclo reproductivo. Se dispone de escasa información sobre parásitos y acción del parasitismo en crustáceos decápodos marinos del litoral de Argentina.

Se ha señalado a bopíridos (Isopoda) parásitos de la cavidad branquial de la centolla $L$. santolla (Vinuesa y Lovrich, 1992); se ha indicado que este tipo de parasitismo puede reducir la frecuencia de 
mudas y debilita al hospedador (O’Brien y van Wyk, 1985). El cirripedio Rhizocephala Briarasaccus callosus, extremadamente modificado, es frecuente como parásito de litódidos. Tiene una estructura en forma de saco y se ubica ventralmente en el itsmo del cefalotórax. El efecto más importante es la castración del animal parasitado, tanto en machos como en hembras, anulando totalmente el proceso reproductivo. La escasa presencia de parásitos en centollas de mayor tamaño, hace suponer un aumento de mortalidad con la edad del animal parasitado; sin embargo en el Canal Beagle se registró una baja incidencia parasitaria con un máximo de $1,4 \%$ (Vinuesa y Lovrich, 1992). Dado la insuficiente experimentación realizada, se sabe muy poco sobre la relación hospedador/huésped y la naturaleza de este fenómeno. Generalmente sólo se conoce la incidencia de animales parasitados en un área de estudio: Martorelli (1992) ha hallado trematodos parásitos en el camarón A. longinaris; Martorelli y Sardella (en prensa) hallaron protozoarios entre los que se destaca una especie del género Vorticella, que utiliza las branquias como sustrato; otros protozoarios apostomados afectan a las branquias formando manchas oscuras. Asimismo Martorelli et al. (en prensa) hallaron un hirudíneo ectoparásito del langostino, así como nematodos, pero no se conocen los efectos que producen sobre el hospedador.

\section{CONSIDERACIONES FINALES}

En los párrafos precedentes se presentó una apretada síntesis sobre los aspectos biológicos, fisiológicos y ecológicos más sobresalientes que influyen o regulan el crecimiento de los crustáceos Decápodos, pero el objetivo principal del artículo ha sido reunir y resumir lo estudiado sobre crustáceos superiores de esta región, tanto a nivel de laboratorio y cultivos experimentales como en poblacional, principalmente de especies de interés pesquero.

La relación talla/edad es fundamental para el análisis poblacional de una especie sometida a explotación pesquera. Estas investigaciones requieren procedimientos especiales en razón de la inexistencia de estructuras duras permanentes en los crustáceos, que registren las marcas del incremento de talla, lo que exige la adopción de métodos distintos a los convencionales para el estudio de la edad y crecimiento.

Surge con claridad por lo mencionado anteriormente, que se deben profundizar los estudios fisiológicos y bioquímicos sobre el crecimiento de los crustáceos, particularmente de las especies como langostino, camarón, centolla, centollón y cangrejos, de alto valor pesquero, lo que facilitará el entendimiento más amplio de su dinámica poblacional y además permitirá disponer de mayores elementos para interpretar las fluctuaciones naturales de sus poblaciones y lograr una explotación sostenida de las mismas.

\section{REFERENCIAS}

Adiyodi, R. 1985. Reproduction and its control. In: D.E.Bliss (ed.), The Biology of Crustacea. Vol. 9, Academic Press, N.Y., pp. 147-217.

Aiken, D.E. 1973. Pro-ecdysis, setal development, and molt prediction in the American lobster (Homarus americanus). J. Fish. Res. Board Canada, 30(9): 1337-1344.

Angelescu, V. y E.E. Boschi. 1959. Estudio biológico-pesquero del langostino de Mar del Plata en conexión con la operación nivel medio. Secret. Mar., Serv. Hidrog. Naval Buenos Aires, 1017: 1-135.

Bertalanffy, L. Von. 1960. Principles and theory of growth. In: W.W. Nowinski (ed.) Fundamental aspects of normal and malignant growth. Elsevier, Amsterdam, pp. 137-259.

Boschi, E.E. 1963. Observaciones sobre la morfología externa del camarón Macrobrachium borelli (Nobili, 1896) (Crustacea, Palaemonidae). Physis (Buenos Aires), 24(67): 165-179.

Boschi, E.E. 1969a. Estudio biológico-pesquero del camarón Artemesia longinaris Bate de Mar del Plata. Bol. Inst. Biol. Mar. (Mar del Plata), 18: 47 pp.

Boschi, E.E. 1969b. Crecimiento, emigración y ecología del camarón comercial Artemesia longinaris Bate. FAO Fish. Rep., 57(3): 833-846.

Boschi, E.E. 1971. Crecimiento en crustáceos superiores. In: Mejia y Moguilesky (ed.). Recientes adelantos en biología, Buenos Aires, pp. 70-76.

Boschi, E.E. 1989. Biología pesquera del langostino del litoral patagónico (Pleoticus muelleri). Contrib. INIDEP (Mar del Plata), No 646: 71 pp.

Boschi, E.E. y M.A. Scelzo. 1971. Ultimos resultados de las investigaciones sobre los peneidos comerciales en la Argentina (Marcaciones, campañas exploratorias y cultivos). CARPAS/5/ D. Téc., 4: $17 \mathrm{pp}$.

Boschi, E.E. y M.A. Scelzo. 1977. Desarrollo larval y cultivo del camarón comercial de Argentina Artemesia longinaris. FAO Inf. Pesca, 159(1): 287-327. 
Boschi, E.E., D.A. Bertuche y J.G. Wyngaard. 1984. Estudio biológico pesquero de la centolla (Lithodes antarcticus) del Canal Beagle, Tierra del Fuego. Argentina. Contrib. INIDEP (Mar del Plata), No441: 72 pp.

Boschi, E.E., M.A. Scelzo y B. Goldstein. 1967. Desarrollo larval de dos especies de crustáceos decápodos en el laboratorio, Pachycheles haigae Rodrigues da Costa (Porcellanidae) y Chasmagnathus granulata Dana (Graspsidae). Bol. Inst. Biol. Mar. (Mar del Plata), 12: 46 pp.

Botsford, L.W. 1985. Models of growth. In: A.M. Wenner (ed.). Factors in Adults Growth. A.A. Balkema, Rotterdam, pp. 171-190.

Bridi, R.J. y J.L. Fenucci. 1992. Alimentación y crecimiento de mysis y postlarvas de langostino (Pleoticus muelleri). Resumenes VIII Jornadas Tecnología y Economía Pesquera, Com. Téc. Mixta del Frente Marítimo, Mar del Plata, pp. 17.

Burkenroad, M.D. 1951. Measurement of the natural growth rates of decapod crustaceans. Proc. Gulf Carib. Fish. Inst., 3: 25-26.

Chamberlain, G.W. y A.L. Lawrence. 1981. Effects of light intensity and male and female ablation on reproduction of Penaeus stylirostris and $P$. vannamei. J. World Maric. Soc., 12(2): 357-372.

Chang, E. 1991. Crustacean molting hormones: cellular effects, role in reproduction and regulation by molt. Inhibiting Hormone. In: P.F. Deloach, W.J. Dougherty and M.A. Davidson (eds.) Frontiers of shrimp research. Elsevier, Amsterdam, pp. 83-105.

Costello, T.J. 1964. Field techniques for stainingrecapture experiments with commercial shrimp. Spec. Scient. Rep. Fish., 484: 1-13.

Costello, T.J. y D.M. Allen. 1961. Survival of stained, tagged and unmarket shrimp in presence of predators. Proc. Fish. Inst., 40 Ann. Sess., 16-20.

Dalley, R. 1980. Effects of non circadian light-dark cycles on the growth and moulting of Palaemon elegans, reared in laboratory. Mar. Biol., 56: 71-78.

Dawson, C.E. 1957. Studies on the marking of commercial shrimp with biological stains. Special Sci. Rep. Fish., 23: 1-24.

Dexter, B.L. 1981. Setogenesis and molting in planktonic crustaceans. J. Plankton Res., 3(1): 1-13.

Díaz, A.C. y A.M. Petriella. 1988. Estudio del crecimiento del langostino Pleoticus muelleri. Rev. Latinoam. Acuic. (Perú), 35: 6-12.

Díaz, A.C. y A.M. Petriella. 1990. Moult staging in the shrimp, Pleoticus muelleri Bate. J. Aqua. Trop., 5: 181-189.
Drach, P. 1939. Mue et cycle d'intermue chez les crustacés décapodes. Ann. Inst. océanogr. Mónaco, 19: 103-391.

Drach, P. 1944. Etude préliminaire sur le cycle d'intermue et son conditionement hormonal chez Leander serratus (Pennant). Bull. Biol. Fr. Belg., 78: $40-62$.

Drach, P. y C. Tchernigovtzeff. 1967. Sur le méthode de la détermination des stades d'intermue et son application générale aux Crustacés. Vie et Milieu, Ser. A, 18: 595-610.

Edsman, L., T. Järvi y B. Niejahr. 1994. The RNA concentration as an index of current growth rate in juvenile signal crayfish, Pacifastacus leniusculus. Nordic J. Freshw. Res., 69: 149-152.

Ennis, G.P. 1972. Growth per moult of tagged lobsters Homarus americanus in Bonavista Bay, Newfoundland. J. Fish. Res. Bd. Canada, 29: 143148.

Farmer, 1973. Age and growth in Nephrops norvegicus (Decapoda; Nephrodidae). Mar. Biol., 23: 315-325.

Fenucci, J.L. y E.E. Boschi. 1975. Contribución al conocimiento biológico del cangrejo comercial de las aguas costeras de la provincia de Buenos Aires Ovalipes trimaculatus (De Haan) (Crustacea, Decapoda, Portunidae). Physis (Buenos Aires), secc. A, 34(89): 291-308.

Fenucci, J.L., M.I. Muller y A.M. Petriella. 1981. Efectos de la alimentación natural y artificial en el crecimiento del camarón Artemesia longinaris Bate. Rev. Latinoam. Acuic. (Perú), 10: 10-18.

Fenucci, J.L., A.M. Petriella y M.I. Muller. 1983. Estudios sobre el crecimiento del camarón Artemesia longinaris Bate alimentado con dietas preparadas. Contribución INIDEP (Mar del Plata), No 424: 17.

Fingerman, S.W. 1985. Non-metal environmental pollutants and growth. In: A.M. Wenner (ed.). Factors in Adult growth. A.A. Balkema, Rotterdam, pp. 219-234.

Frantzis, A., A. Gremare y G. Vetion. 1992. Growth rates and RNA:DNA ratios in Paracentrotus lividus (Echinodermata: Echinoidea). J. exp. mar. Biol. Ecol., 156: 125-138.

Galarza, C.M. y J.L. Fenucci. 1992. Crecimiento y supervivencia de protozoeas de langostino (Pleoticus muelleri) alimentadas con diferentes concentraciones de Chaetoceros gracilis. Resúmenes VIII Jornadas Tecnología y Economía Pesquera, Com. Téc. Mixta del Frente Marítimo, Mar del Plata, pp. 16. 
Haran, N.S., J.L. Fenucci y A.C. Díaz. 1992. Efectos de la temperatura y la salinidad sobre el crecimiento y la supervivencia de camarón (Artemesia longinaris) y el langostino (Pleoticus muelleri). Frente Marítimo, 11: 79-84.

Hartnoll, R.G. 1982. Growth. In: D. Bliss (ed.). The Biology of Crustacea, Vol. 2. Academic Press, N.Y., pp. 111-185.

Hartnoll, R.G. 1985. Growth, sexual maturity and reproductive output. In: A.M. Wenner (ed.). Factors in Adults Growth. A.A. Balkema, Rotterdam, pp. 101-128.

Hiatt, R.W. 1948. The biology of the lined shore crab, Pachygrapsus crassipes Randall. Pacif. Sci., 2: 135-213.

Hoglund, H. 1943. On the biology and larval develpment of Leander squilla (L.) forma typica de MAn. Svenska Hydrografisk-Biologiska Kommissionens Skrifter. Ny Serie: Biol., 2(6): 1-44.

Hopkins, P.M. 1985. Regeneration and relative growth in the fiddler crab. Crustacean Issues 3. In: F.R. Schram (ed.). Factors in Adult Growth. A.A. Balkema, Rotterdam, pp. 265-275.

Klima, E.F. 1965. Evaluation of biological stains, inks and fluorescent pigments as mark for shrimp. Fish Wildlife Serv. Spec. Scient. Rep., 511: 1-8.

Kurata, H. 1962. Studies on the age and growth of crustaces. Bull. Hokkaido Reg. Fish. Res. Lab., 24: 1-115.

Lachaise, F., A. Le Roux, M. Hubert y R. Lafont, R. 1993. The molting gland of crustaceans: localization, activity, and endocrine control (a review). J. Crust. Biol., 13(2): 198-234.

Lindner, M.J. 1953. Estimation of growth rate in animals by marking experiments. US Fish. Bull., 78(54): 65-69.

Lidner, M.J. y W.W. Anderson. 1956. Growth, migrations, spawning and size distribution of shrimp Penaeus setiferus. US Dept. Int. Fish. Wild. Serv. Fish. Bull., 106: 555-645.

Lombardo, R.J., L. Ferrari y J.H. Vinuesa. 1982. Efectos del etil parathion y DDVP sobre larvas de centolla Lithodes antarcticus Jacquinot. Ecosur, 9(18): 141-151.

López, A.V. y J.L. Fenucci. 1988. Acción de la temperatura y algunos contaminantes en el crecimiento del camarón Artemesia longinaris Bate. Rev. Latinoam. Acuic. (Perú), 38: 109-116.

Lovrich, G.A. 1991. Reproducción y crecimiento del centollón, Paralomis granulosa (Crustacea, Anomura, Lithodidae) en el Canal Beagle. Tesis doctoral. Fac. Cs. Exactas y Naturales, Universidad de Buenos Aires, 160 pp.

Lovrich, G.A. y J.H. Vinuesa. 1993. Reproductive biology of the false southern king crab (Paralomis granulosa, Lithodidae) in the Beagle Channel, Argentina. US Fish. Bull., 9: 664-675.

Lovrich, G.A y J.H. Vinuesa. 1995. Growth of juvenile false southern kimg crab Paralomis granulosa (Anomura, Lithodidae) in the Beagle Channel, Argentina. Sci. Mar., 59(1): 87-94.

Mallo, J.C. y E.E. Boschi. 1982. Contribución al conocimiento del ciclo vital del camarón Peisos petrunkevitchi de la región de Mar del Plata, Argentina (Crustacea, Decapoda, Sergestidae). Physis (Buenos Aires). Sec. A41 (100): 85-98.

Mallo, J.C., J.L. Fenucci, C.M. Galarza, R.J. Bridi, G. Sarlo y A. Fernández Herrero. 1992. Engorde de postlarvas del camarón (Macrobrachium rosenbergii) en estanques externos en el área de Mar del Plata. Resumenes VIII Jornadas Tecnología y Economía Pesquera, Com. Téc. Mixta del Frente Marítimo, Mar del Plata, pp. 11.

Martorelli, S.R. 1992. Parasites of commercial shrimps and fishes in argentine sea: On the adult and metacercaria of Opecoloides felicias n.sp. (Digenea: Opecoelidae). Mem. Inst. Osvaldo Cruz, Rio de Janeiro, 87(1): 43-48.

Martorelli, S.R. y N.H. Sardella. En prensa. Protozoos ciliados parásitos branquiales presentes en Artemesia longinaris y Pleoticus muelleri (Crustacea, Decapoda). Rev. Museo La Plata (Argentina).

Martorelli, S.R., J. Etchegoin y J.C. Mallo. En prensa. Presencia de un hirudineo del género Stibarobdella sobre el langostino Pleoticus muelleri (Crustacea, Decapoda, Solenoceridae). Neotropica (Argentina).

Marullo, F., D.A. Emiliani, C.W. Caillouet y S.A. Clark. 1976. A vinyl streamer tag shrimp (Penaeus spp). Trans. Am. Fish. Soc., 105(6): 658-663.

Mauchline, J. 1976. The Hiatt growth diagram for Crustacea. Mar. Biol., 35: 79-84.

Mauchline, J. 1977. Growth of shrimps, crabs and lobsters, and assesment. J. Const. int. Explor. Mer, 37: 163-169.

McVean, A. 1982. Autotomy. In: D.R. Bliss (ed). The Biology of Crustacea. Vol. 4. Academic Press, N.Y., pp. 107-132.

Moss, S.M. 1994a. Growth rates, nucleic acid concentrations, and RNA/DNA ratios of juvenile white shrimp, Penaeus vannamei Boone, fed different algal diets. J. exp. mar. Biol. Ecol., 182: 193-204.

Moss, S.M. 1994b. Use of nucleic acids as indicators of 
growth in juvenile white shrimp, Penaeus vannamei. Mar. Biol., 120: 359-367.

Müller, M.I., J.L. Fenucci y J.H. Magnaterra. 1986. Estudio sobre la influencia de diversas condiciones ambientales en el crecimiento y la supervivencia de Artemesia longinaris Bate. Rev. Latinoam. Acuic. (Perú), 28: 7-13.

O'Brien, J. y P. Van Wyk. 1985. Effects of crustacean parasitic castrators (Epicaridean Isopods and Rhizocephalan Barnacles) on growth of crustacean hosts. In: A.M. Wenner (ed.). Factors in Adult Growth. A.A. Balkema, Rotterdam, pp. 191-218.

Olmstead, J.M. y J.P. Baumberger. 1923. Form and growth of grapsoid crabs. A comparison of the form of three species of grapsoid crabs and their growth at moulting. J. Morphol., 38: 279-294.

Petriella, A.M. 1984. Estudio del ciclo de la muda del camarón Artemesia longinaris Bate. I. Setogénesis. Physis (Buenos Aires) Secc. A, 42(103): 93-100.

Petriella, A.M. 1986. Estudio del ciclo de la muda del camarón Artemesia longinaris Bate. II. Crecimiento y frecuencia de muda. Rev. Latinoam. Acuic. (Perú), 29: 11-21.

Petriella, A.M. 1987. Estudio del ciclo de la muda del camarón Artemesia longinaris: descripción, crecimiento y relación con el colesterol. Tesis doctoral. Fac. Cs. Exactas y Naturales, Universidad de Buenos Aires, 176 pp.

Petriella, A.M. En prensa. Influencia del fotoperíodo sobre el ciclo de muda y el crecimiento del camarón argentino Artemesia longinaris (Crustacea, Decapoda, Penaeidae). Rev. Latinoam. Acuic. (Perú).

Petriella, A.M. y R.J. Bridi. 1992. Variaciones estacionales del ciclo de muda y la maduración ovárica del camarón Artemesia longinaris Bate. Frente Marítimo, 11(A): 85-92.

Petriella, A.M., M. I. Müller, J.L. Fenucci y M. Sáez. 1984. Influence of dietary fatty acids and cholesterol on the growth and survival of the argentine prawn, Artemesia longinaris Bate. Aquaculture, 37: 11-20.

Phillips, B.F., M.J. Palmer, R. Cruz y J.T. Trendall. 1992. Estimating growth of the spiny lobsters Panulirus cygnus, P. argus and P. ornatus. Australian J. Mar. Fresw. Res., 43: 1177-1188.

Reaka, M.L. 1975. Molting in stomatopod crustaceans. I. Stages of the molt cycle and morphology. J. Morphol., 146: 55-80.

Rousenfell, G.A. 1963. Marking fish and invertebrates. Fish and Wildlife Ser. Fish. Leaflet, 549: 1-12.
Ruello, N.V. 1975. Geographical distribution, growth and breeding migration of the Eastern Australian king prawn Penaeus plebejus Hess. Aust. J. Mar. Freshw. Res., 26: 343-354

Sheehy, M.R.J. 1990a. Widespread occurence of fluorescent morphological lipofucsin in the crustacean brain. J. Crust. Biol., 10: 613-622.

Sheehy, M.R.J. 1990b. Potential of morphological lipofucsin age-pigment as an index of crustacean age. Mar. Biol., 107: 439-442.

Sheehy, M.R.J., E. Cameron, G. Mardsen y J. McGrath. 1995. Age structure of female giant tiger prawns Penaeus monodon as indicated by neuronal lipofucsin concentration. Mar. Ecol. Prog. Ser., 117: 59-63.

Skinner, D.M. 1985. Molting and regeneration. In: D. Bliss (ed.). The Biology of Crustacea. Vol. 9. Academic Press, N.Y., pp. 43-146.

Skinner, D.M., D.E. Graham, C.A. Holland, D.L. Mykles, C. Soumoff y L.H. Yamaoka. 1985. Control of molting in Crustacea. In: A.M. Wenner (ed.). Factors in adult growth. A.A. Balkema, Rotterdam, pp. 3-14.

Spivak, E. 1988. Moult and growth in a common South-American littoral crab Cyrtograpsus angulatus. J. Nat. Hist., 22: 617-629.

Spivak, E. 1990. Limb regeneration in a common South-American littoral crab Cyrtograpsus angulatus. J. Nat. Hist., 24: 393-402.

Spivak, E. y M.A. Politis. 1989. High incidence of limb autotomy in a crab population from a coastal lagoon in the province of Buenos Aires, Argentina. Can. J. Zool., 67: 1976-1985.

Stevenson, J.R. 1985. Dynamics of the integument. In: D. Bliss (ed.). The Biology of Crustacea. Vol. 9. Academic Press, N.Y., pp. 2-42.

Tagatz, M.E. 1968. Growth of juvenile crabs, Callinectes sapidus Rathbun, in the St. Johns River, Florida. US Fish. Bull., 67: 281-288.

Vinuesa, J.H., L.I. Comoglio y G.A. Lovrich. 1990. Growth of inmature Southern king crab, Lithodes santolla in the Beagle channel. Proc. Int. Symp. King and Tanner Crabs. Nov. 1989, Anchorage, Alaska: 259-271.

Vinuesa, J.H., G.A. Lovrich y L.I. Comoglio. 1992. Biología y pesca de la centolla en el Canal Beagle, Tierra del Fuego, Argentina. Recomendaciones para su manejo. Contrib. Cient. CADIC (Ushuaia), 15: 1-26.

Woodland, B. 1966. Electronic tagging. Trade news, Feb. 1966. Depart. Fish. Can. (Ottawa), 13 pp. 
Wright, D.A. y E.W. Hetzel. 1985. Use of RNA:DNA ratios as an indicator of nutritional stress in the American oyster Crassostrea virginica. Mar. Ecol. Prog. Ser., 25: 199-206.

Wyngaard, J.G. y D.A. Bertuche. 1982. Algunos aspectos de la biología pesquera del langostino (Pleoticus muelleri) de la Bahía Blanca y un análisis del desembarco comercial en el período 1955-1979. Rev. Invest. Des. Pesq. (Mar del Plata), 3: 59-76.

Yano, I. y S. Kobayashi. 1969. Calcification and age determination in Crustacea. 1. Possibility of age determination in crabs on the basis of number of lamellae in cuticles. Bull. Jap. Soc. Sci. Fish., 35: 34-42.

Recibido el 13 de mayo de 1996.

Aceptado el 29 de julio de 1996. 